\title{
A common human variant of GIPR improves systemic glucose homeostasis in a sexual dimorphic manner
}

Authors: Lucie Yammine ${ }^{1}$, Belén Picatoste ${ }^{1 \#}$, Nazish Abdullah ${ }^{1 \#}$, David Soares ${ }^{1}$, Rosemary Leahey ${ }^{1}$, Nicolás Gómez-Banoy ${ }^{2}$, Carolina Rosselot ${ }^{3}$, Jennifer Wen ${ }^{1}$, James C. Lo ${ }^{2}$, Adolfo Garcia-Ocaña ${ }^{3}$, Timothy E. McGraw ${ }^{1,4,5^{*}}$

\section{Affiliations}

${ }^{1}$ Department of Biochemistry, Weill Cornell Medical College, New York, NY, 10065, USA

${ }^{2}$ Weill Center for Metabolic Health and Division of Cardiology, Department of Medicine, Weill Cornell Medicine, New York, NY, 10021, USA

${ }^{3}$ Diabetes, Obesity, and Metabolism Institute, Icahn School of Medicine at Mount Sinai, New York, NY, 10029, USA.

${ }^{4}$ Department of Cardiothoracic Surgery, Weill Cornell Medical College, New York, NY, 10065, USA

${ }^{5}$ Lead contact

\section{Author list footnotes}

\# contributed equally.

*Correspondence: temcgraw@med.cornell.edu 


\section{Summary}

Glucose-dependent insulinotropic polypeptide (GIP), an incretin hormone, has a role in controlling postprandial metabolic tone. A GIP receptor (GIPR) variant (Q354, rs 1800437) is associated with enhanced glucose tolerance and a lower BMI. To isolate the contribution of GIPR in metabolic control, we generated a mouse model of the GIPR-Q354 variant. Islets isolated from both male and female GIPR-Q variant mice have an enhanced glucose sensitivity and enhanced GIP response. In whole animal studies only female GIPR-Q variant mice are more glucose tolerant, whereas males have normal glucose tolerance but an enhanced sensitivity to GIP. In both sexes postprandial GIP levels are reduced, revealing feedback between the sensitivity of GIP target tissues and the secretion of GIP from intestinal endocrine cells. In line with the association of the variant with reduced BMI, GIPR-Q350 mice are resistant to dietinduced obesity. GIPR, a GPCR, is coupled to elevated cAMP. Prior studies have established altered post-activation traffic of the GIPR-Q variant without a change in affinity for GIP or in CAMP production. Consequently, our data link altered intracellular traffic of the GIPR-Q variant with GIP metabolic control of metabolism. Incretin hormone action is targeted in treatment of insulin-resistance, and our findings support pharmacologic targeting the GIPR to mimic the altered trafficking of the GIPR-Q variant as a potential strategy to enhance GIP metabolic effects in treatment of insulin resistance.

\section{Keywords}

GIP; GIP receptor; glucose homeostasis; incretin; obesity 


\section{Introduction}

The glucose-dependent insulinotropic peptide (GIP) is a hormone secreted by the K cells of the intestinal epithelium in response to the caloric content of the chyme (Buchan et al., 1978; Drucker, 2006). GIP and another gut-derived hormone, Glucagon-like Peptide 1 (GLP-1), which together are referred to as incretin hormones, contribute significantly to control of postprandial metabolic tone (Baggio and Drucker, 2007; Kim and Egan, 2008; Nauck and Meier, 2018). Insulin secreting pancreatic $\beta$ cells are a principle target of incretin hormone action, with the incretins enhancing glucosestimulated insulin secretion (Dupre et al., 1973; Holst and Gromada, 2004). The GIP receptor (GIPR), which is more widely expressed than the GLP-1 receptor (Usdin et al., 1993), exerts extra-pancreatic roles in neurogenesis (Faivre et al., 2011), fat accumulation in the adipose tissue (Lamont and Drucker, 2008) and bone formation (Xie et al., 2007).

GIPR is a class B G protein-coupled receptor (GPCR) linked to adenylate cyclase activation via Gs (Mayo et al., 2003). Elevation of 3'-5'-cyclic adenosine monophosphate (cAMP) downstream of GIPR activation enhances glucose-stimulated insulin secretion (Yabe and Seino, 2011). Post activation traffic of GPCRs is crucial for sculpting response to the signal (Pavlos and Friedman, 2017). GIPR trafficking has been analyzed in a variety of cell types (Ismail et al., 2015; Tseng and Zhang, 2000; Wheeler et al., 1999). In our previous studies of GIPR in adipocytes, a cell type that natively expresses the GIPR, we have shown that GIPR, independent of ligand stimulation, is constitutively internalized and recycled back to the plasma membrane (Mohammad et al., 2014). GIP stimulation slows recycling of the receptor without affecting GIPR internalization (Abdullah et al., 2016; Mohammad et al., 2014). The slowed recycling is achieved by diverting the active receptor from the endosomal recycling pathway to the slower Trans Golgi Network (TGN) recycling route (Abdullah et al., 2016). The reduced recycling rate of active GIPR induces a transient downregulation of GIPR from the plasma membrane that is reversed when GIP-stimulation is terminated (Mohammad et al., 2014). 
Genome-wide association studies have identified several naturally occurring variants of GIPR. GIPR-Q354 (SNP rs1800437), a substitution glutamine for glutamic acid at position 354 of human GIPR (Sauber et al., 2010; Saxena et al., 2010; Vogel et al., 2009), is a variant with a relatively high allele frequency of 0.2 in European descents. Homozygosity for GIPR-Q354 is associated with lower BMI in different meta-analyses, whereas the predominant GIPR form (GIPR-E354) has been associated with a higher susceptibility to obesity (Berndt et al., 2013; Graff et al., 2017; Vogel et al., 2009). Individuals homozygous for the GIPR-Q354 variant have a reduced C-peptide excursion in response to an oral glucose tolerance test, as well as a reduced GIP and insulin concentrations, documenting effects of the GIPR-Q354 variant on $\beta$ cell biology (Almgren et al., 2017). In Danish perimenopausal women, carriers of the GIPR-Q354 variant were shown to have a significantly lower bone mineral density as well as a higher bone fracture risk (Torekov et al., 2014).

Substitution of glutamine for a glutamic acid at position 354 of GIPR, which is in the 6 transmembrane domain, does not affect the affinity for GIP nor GIP-stimulated increase in cAMP, demonstrating the substitution does not affect the most receptor proximal aspects of GIP-stimulated GIPR signaling (Abdullah et al., 2016; Almind et al., 1998; Gabe et al., 2019; Mohammad et al., 2014). However, we have demonstrated postactivation trafficking differences between GIPR-E354 and GIPR-Q354. In adipocytes, the GIPR-Q354 variant undergoes enhanced GIP-stimulated downregulation from the plasma membrane coupled with an enhanced trafficking of GIPR to the TGN (Abdullah et al., 2016; Mohammad et al., 2014). Consequences of the altered post-activation trafficking of GIPR-Q354 are an increased localization of active GIPR-Q354 in the TGN and a slower repopulation of plasma membrane GIPR-Q354 following termination of GIP stimulation, thereby resulting in an enhanced and prolonged downregulation of GIPR-Q354 relative to GIPR-E354 (Mohammad et al., 2014).

In this study we generated a mouse model of the human GIPR-Q354 variant, in which glutamine is substituted for glutamic acid at position 350 of the mouse GIPR (equivalent to human GIPR-Q354). Using this mouse model system of a human genetic variant, we reveal a critical role of the amino acid at position 354 of the mouse GIPR in the biology 
of $\beta$ cells. Female GIPR-Q350 mice have a significant enhancement of glucose tolerance as compared to WT C57BL/6J female mice (GIPR-E354). In contrast, there is no difference in glucose tolerance between the two genotypes of male mice. However, male GIPR-350 mice have a significant increase in response to GIP in a glucose tolerance test. Thus, there is a sexual dimorphism in the impact of GIPR-Q350 on whole body glucose metabolism. Female GIPR-Q350 islets have increased glucose-stimulated insulin secretion and an increased response to GIP, consistent with the differences between genotypes in the control of whole body glucose homeostasis of female mice. Male GIPR-Q350 islets, like female GIPR-Q350 islets, secrete more insulin in response to glucose and are more responsive to GIP stimulation than male GIPR-WT islets, indicating the sexual dimorphism is not recapitulated in the isolated islets. Finally, male GIPR-Q350 mice gain less weight on a high fat diet and are correspondingly less susceptible to the metabolic effects of over nutrition than are GIPR-WT male mice. These findings contribute to a more complete understanding of the impact of GIPRQ354 variant on glucose homeostasis that could be leveraged to better pharmacologically target GIPR biology in treatment of metabolic disease. 


\section{Results}

\section{GIPR-Q354 has an enhanced desensitization period as compared to GIPR-E354}

We studied the trafficking behaviors of GIPR-E354 and GIPR-Q354 variants in $\beta$ cells, a major target cell of GIP action, using the previously characterized HA-GIPR-GFP construct (Mohammad et al., 2014) expressed in the MIN6 $\beta$ cell line. GIP stimulation resulted in a 30\% downregulation of plasma membrane GIPR-E354 (Figure 1A). In unstimulated cells, GIPR-Q354 expression at the plasma membrane was comparable to that of GIPR-E354; however, GIP-stimulated downregulation of GIPR-Q354 was significantly enhanced, demonstrating differences in post-activation trafficking between GIPR-E354 and GIPR-Q354. As we have previously shown in adipocytes, both GIPRE354 and GIPR-Q354 activated by GIP traffic through the TGN (Figure 1B).

Downregulation of both GIPR-E354 and GIPR-Q354 resulted from a slowing of activated GIPR recycling back to the plasma membrane (Figure 1C). Fitting the data to an exponential rise to a plateau revealed that both GIPR-E354 and GIPR-Q354 were constitutively recycled to the plasma membrane in unstimulated cells at similar rates (recycling rate constants of 0.026 and $0.029 \mathrm{~min}^{-1}$, respectively). GIP stimulation induced a near twofold slowing of GIPR-E354 recycling $\left(0.015 \mathrm{~min}^{-1}\right)$, whereas the recycling of the GIPR-Q354 was reduced fourfold $\left(0.007 \mathrm{~min}^{-1}\right)$. In addition, about $30 \%$ of the internalized activated GIPR-Q354 does not recycle, reflected in the reduced plateau level for GIP-stimulated GIPR-Q354 (Figure 1C). These data demonstrate that both GIPR-E354 and GIPR-Q354 constitutively recycle in unstimulated MIN6 $\beta$ cells, and that GIP stimulation slows the recycling of both GIPR variants, albeit with a significantly more pronounced effect on GIPR-Q354, findings that are in agreement with previous studies of GIPR in cultured adipocytes (Abdullah et al., 2016; Mohammad et al., 2014).

An additional consequence of the enhanced downregulation of GIPR-Q354 is that when GIP stimulation was terminated, repopulation of the plasma membrane with GIPR-Q354 takes about four times longer than for GIPR-E354 (Figure 1D). However, the plasma membrane levels of GIPR-Q354 are ultimately restored to the pre-stimulus level upon 
termination of GIPR stimulation, albeit at a slower rate. Thus, the approximate $30 \%$ of GIPR-Q354 that does not recycle in stimulated cells (reduced plateau Figure 1C) does recycle upon termination of GIPR stimulation (Figure 1D).

In sum, these analyses demonstrate that in MIN6 $\beta$ cells, as is the case in adipocytes, there are significant differences between the post-activation trafficking of GIPR-E354 and the GIPR-Q354 variant associated with metabolic alterations in humans.

\section{Generation of GIPR-Q350 mice}

Position 350 of the mouse GIPR is equivalent to position 354 of human GIPR.

C57BL/6J mice have a glutamic acid at position 354 (GIPR-WT), and therefore are equivalent to the most common human GIPR protein sequence. To probe whether the differences in post-activation trafficking between GIPR-WT and the GIPR-Q354 variant, discovered in our studies of cultured cells, impacts GIP control of metabolic tone, we used CRISPR-CAS9 technology to generate GIPR-Q350 variant C57BL/6J mice. Here we report the metabolic characterization of male and female mice homozygous for GIPR-WT in comparison to GIPR-Q350 homozygous mice.

\section{GIPR-Q350 female mice are glucose tolerant}

Female GIPR-Q350 mice had comparable body weight gain over time when fed a normal chow diet, and there were no differences in random blood glucose between the genotypes (Figures 2A and 2B). Whole body insulin sensitivity did not differ between the two genotypes of female mice when measured by intraperitoneal insulin tolerance test (IP-ITT) (Figure 2C). Similarly, GIPR-WT and GIPR-Q350 female mice exhibited an equivalent glucose-lowering response when co-injected IP with insulin and GIP (Figure 2D). Therefore, GIPR-Q350 did not significantly alter whole-body insulin sensitivity of female mice as determined by IP-ITT.

GIPR-Q350 female mice, however, were significantly more glucose tolerant than GIPRWT mice in an oral glucose tolerance test (OGTT) (Figure 3A). Although the enhanced glucose tolerance was not associated with post-stimulation differences in plasma insulin 
levels between the genotypes, there were significant reductions in plasma GIP levels of GIPR-Q350 mice (Figures 3B and 3C). Because postprandial GIP levels contribute significantly to the amount of insulin secreted from $\beta$ cells (the incretin effect), the unchanged insulin levels in context of significantly lower GIP levels was unexpected.

To more directly probe GIP action in Q350-GIPR mice, we performed an intraperitoneal glucose tolerance test (IP-GTT) in which we injected glucose alone or glucose plus GIP. In this protocol we assess the contribution of the exogenous GIP on glucose tolerance. As expected, the GIPR-WT female mice exhibited a significantly lower glucose excursion when co-injected with glucose plus GIP as compared to the glucose alone, demonstrating the contribution of GIP to blood glucose lowering (Figures 3D and 3E). Consistent with the increased glucose tolerance in the OGTT, GIPR-Q350 female mice also had an enhanced glucose tolerance in an IP-GTT. In fact, the glucose tolerance of GIPR-Q350 mice was similar to that of GIPR-WT mice co-injected with glucose and GIP (Figures 3D and 3E). There was no difference in glucose tolerance between GIPRQ350 female mice injected with glucose or with glucose and GIP, which suggests that the degree of enhanced response to glucose alone of the GIPR-Q350 mice reduces the potential window of any GIP effect on lowering blood glucose. In that context, it was not surprising that female GIPR-Q350 mice were also unresponsive to GLP-1 (the other incretin hormone) in an IP-GTT (Figures S1A and S1B).

In both genotypes of female mice, plasma insulin levels were elevated when GIP was co-injected with glucose as compared to glucose alone (Figure 3F). However, there was a trend to an elevation of plasma insulin levels of GIPR-Q350 mice co-stimulated with glucose and GIP above that in similarly treated GIPR-WT mice ( $p=0.07)$, suggesting GIPR-Q350 female mice have an increased sensitivity to GIP. Unexpectedly, the increased glucose tolerance of GIPR-Q350 female mice, as compared to GIPR-WT mice, was not reflected in a significant difference in plasma insulin levels between the two genotypes of mice injected with glucose alone (Figure 3F).

We monitored glucose-stimulated insulin secretion (GSIS) in isolated islets to more directly assess potential differences between the two genotypes in the response of $\beta$ cells to GIP. In agreement with the in vivo data, GSIS of female GIPR-Q350 islets 
revealed an enhanced sensitivity to glucose as compared to female GIPR-WT islets (Figure 3G). In addition, female GIPR-Q350 islets secrete more insulin when costimulated with high glucose and GIP than when stimulated with high glucose alone. These data establish cell-intrinsic differences between GIPR-Q350 and GIPR-WT islets in response to both glucose stimulation and glucose plus GIP stimulation. Total insulin was the same in the islets of both genotypes, demonstrating the GSIS differences between genotypes are related to differences in response/release of insulin not the amount of insulin available for secretion (Figure 3H). Of note, there was no enhanced insulin secretion from GIPR-Q350 islets, as compared to GIPR-WT islets, at low glucose levels (3 mM), demonstrating that the effects of GIPR-Q350 are limited to enhancing GSIS (Figure 3G).

Despite the differences in responsiveness of the GIPR-Q350 islets to glucose and to GIP, there were no prominent differences in the cellular organization of the islets, with the insulin expressing $\beta$ cells segregated to the interior of islets and glucagon expressing $\alpha$ cells to the periphery (Figure 3I). At the mRNA level there were no differences in the expression of Gipr, Insulin, Glp1r, Glut2 or Glucokinase, the latter two are key genes for response of $\beta$ cells to glucose (Figure 3J).

\section{GIPR-Q350 males are GIP hypersensitive}

We next characterized the effect of GIPR-Q350 on male mice. Male GIPR-Q350 mice had comparable body weight gain when fed a normal chow diet, and there were no differences in random blood glucose between the genotypes (Figures 4A and 4B). As was the case for female mice, GIPR-Q350 male mice had the same insulin sensitivity as GIPR-WT mice in both an IP-ITT and an IP-ITT in which GIP was co-administered with insulin (Figures 4C and 4E).

Moreover, in contrast to the GIPR-Q350 female mice, glucose tolerance of GIPR-Q350 male mice was comparable to GIPR-WT mice in an OGTT (Figure 5A). However, as was the case for female mice, plasma GIP levels were reduced in GIPR-Q350 male mice as compared to GIPR-WT mice without a difference in insulin levels (Figures 5B and 5C). In an IP-GTT, GIPR-WT and GIPR-Q350 male mice had similar glucose 
tolerances when injected with glucose alone, whereas GIPR-Q350 male mice had a significantly enhanced glucose tolerance when co-injected with glucose and GIP (Figures 5D and 5E). Unexpectedly, despite the differences in plasma glucose, the plasma insulin levels between the two genotypes after glucose plus GIP co-injection were similar (Figure 5F). The enhanced GIP effect on glucose levels without a change in circulating insulin levels likely arises from the complex homeostatic control of plasma insulin.

These data reveal a sexual dimorphism of the GIPR-Q350 variant. Male mice homozygous for the GIPR-Q350 variant are more responsive to GIP but with a normal response to IP glucose. Whereas female mice homozygous for the GIPR-Q350 variant are more responsive to IP glucose, to such an extent that there is no effect on blood glucose excursion when glucose and GIP are co-injected.

GIPR-Q350 male mice have the same response to GLP-1, the other incretin hormone, as GIPR-WT mice, establishing that the effect of GIPR-Q350 is specific to GIP (Figures S1C and S1D).

Despite male GIPR-Q350 mice not having an enhanced glucose tolerance in an IP-GTT with glucose alone (Figures 5D and 5E), male GIPR-Q350 islets secreted more insulin when stimulated with glucose, which was further enhanced when stimulated with glucose and GIP (Figure 5G). Thus, there are cell-intrinsic changes in male GIPR-Q350 $\beta$ cells that lead to changes in the regulation of insulin secretion; however, these differences identified ex vivo are not recapitulated in vivo likely due to the influence of other factors that contribute to homeostatic regulation of whole-body glucose metabolism.

As was the case for female islets, there were no differences in insulin content in islets or in islet morphology between the genotypes (Figures $5 \mathrm{H}$ and $5 \mathrm{I}$ ). At the mRNA level there were no differences in the expression of Gipr, Insulin, Glp1r, Glut2 and Glucokinase (Figure 5J).

\section{GIPR-Q350 males are resistant to diet-induced obesity}


In humans, GIPR-E354 allele is associated with an increased obesity risk (Berndt et al., 2013; Vogel et al., 2009). To explore the roles of the GIPR-Q350 variant in weight control of mice, we challenged male mice of both genotypes with a $60 \%$ high-fat diet (60\% fat, $20 \%$ proteins, $20 \%$ carbohydrates). We restricted study of HFD to male mice because of the reported variable impact of HFD on female C57BL/6J mice (Harris et al., 2003; Hwang et al., 2010; Johnston et al., 2007; Tortoriello et al., 2004). GIPR-WT mice gained significantly more weight than GIPR-Q350 mice (Figure 6A). Magnetic resonance imaging of body fat revealed that HFD-fed GIPR-Q350 mice have a lower fat mass and no change in lean mass as compared to GIPR-WT mice (Figure 6B). Of note, the fat mass of HFD-fed GIPR-Q350 males, $16.6 \%$ of body weight, was comparable to values reported in the literature for fat mass of similarly aged WT mice fed a normal chow diet, $\sim 16 \%$ of body mass (Pedroso et al., 2019; Sharma et al., 2019), demonstrating the near complete blunting of weight gain in GIPR-Q350 male mice on HFD.

After 17 weeks on a high fat diet, the GIPR-Q350 mice had lower weights (Figure 6C), fasting blood glucose (Figure 6D) and responded to oral glucose challenge with an increase in insulin and were significantly more glucose tolerant in an OGTT (Figures 6E and 6F). All these differences are in line with the reduced weight of GIPR-Q350 mice (Figure 6C). There were no differences in circulating GIP between GIPR-WT and GIPRQ350 mice on HFD and in both genotypes the levels of circulating GIP were over tenfold elevated as compared to male mice on normal chow diet (Figure 6G).

Despite the significant difference in weight gain between GIPR-WT and GIPR-Q350 male mice, there were no significant differences between the genotypes in food consumed, energy expenditure, physical activity, respiratory exchange ratio, energy loss to feces or digestive efficiency between GIPR-WT and GIPR-Q350 males (Figures S2A-S2D and S2F-S2H). The one difference we observed was a significant increase of water intake by GIPR-Q350 male mice (Figure S2E). 


\section{Discussion}

GWAS studies have identified GIPR variants linked to T2D and obesity (Enya et al., 2014; Nitz et al., 2007; Saxena et al., 2010; Turcot et al., 2018; Wen et al., 2012). In particular, homozygosity for GIPR-Q354 is correlated with lower BMI and improved glucose homeostasis (Almind et al., 1998; Berndt et al., 2013; Graff et al., 2017; Vogel et al., 2009). We generated an isogenic mouse model of the naturally occurring human GIPR-Q354 variant to isolate the effect of the variant on whole body metabolic control. GIPR-Q350 male mice have a normal glucose tolerance and an enhanced sensitivity to GIP, whereas GIPR-Q350 female mice have an enhanced glucose tolerance that obfuscates any further effect of GIP on glucose clearance. Male mice have a normal response to GLP-1, documenting the effect is specific for GIP. Because of the enhanced glucose tolerance of female GIPR-Q350 mice, we were unable to assess GLP-1 activity in female mice. Human studies have not reported sexual dimorphism for GIPR-Q354 in glucose tolerance (Almind et al., 1998), or susceptibility to obesity and diabetes (Berndt et al., 2013; Graff et al., 2017; Vogel et al., 2009).

Islets isolated from male and female GIPR-Q350 mice have enhanced sensitivity to glucose as well as an enhanced response to GIP, demonstrating that GIPR-Q350 $\beta$ cells are re-programmed for a more robust response to elevated glucose as well as an enhanced acute response to GIP. Because these ex vivo effects are cell-intrinsic, that is independent of extra-islet factors that modify $\beta$-cell response in vivo, they likely reflect transcriptional changes in the GIPR-Q350 $\beta$-cells. In addition to its acute effects on $\beta$ cells, GIP regulates transcriptional programs in $\beta$-cells (Ehses et al., 2003; Kim et al., 2008). Our data support the hypothesis that in addition some key element(s) of the glucose-responsive machinery of $\beta$-cells is impacted by GIPR-Q350. The differences in response to glucose and GIP of GIPR-Q350 islets are independent of gross differences in islet size, morphology, or total insulin content and in the mRNA levels of GIPR, GLP-1 receptor, GLUT2 and glucokinase. GIPR-Q350 islets provide an experimentally tractable system to define the impact of this variant on $\beta$-cell glucose sensing and response. 
Activation of GIPR is linked, via Gs, to elevated CAMP, which is required for GIP enhancement of GSIS. The affinity of GIP for GIPR as well as cAMP generated downstream of GIPR are not significantly affected by the Q354 substitution (Abdullah et al., 2016; Almind et al., 1998; Gabe et al., 2019; Mohammad et al., 2014). However, Q354 substitution has been shown to impact GIPR trafficking (Abdullah et al., 2016; Mohammad et al., 2014). In cultured $\beta$-cells trafficking of activated GIPR-Q354 to the TGN was enhanced relative to the GIPR-WT, similar to its behavior in cultured adipocytes that natively express GIPR (Abdullah et al., 2016; Mohammad et al., 2014).

The specific pathways linking GIP (and GLP-1) to enhanced insulin secretion have not been worked out in molecular detail. GIPR activation results in elevated $\mathrm{Ca}^{2+}$ downstream of cAMP activation of protein kinase $A(P K A)$ and cAMP-activated guanine nucleotide exchange factor/exchange protein directly activated by cAMP (EPAC) (Leech et al., 2010; Seino and Shibasaki, 2005). PKA and EPAC have been reported to have direct effects on proteins that regulate insulin granule movement and fusion with the plasma membrane suggesting possible molecular mechanisms for GIP enhancement of insulin secretion (Chepurny et al., 2010; Shibasaki et al., 2007; Song et al., 2011). In addition to these acute effects, GIP also has $\beta$-cell trophic effects mediated by the promotion of a pro-survival gene transcription program downstream of PKA phosphorylation of the transcription regulator CAMP-response element binding protein (CREB) (Kim et al., 2008; Trümper et al., 2001). In this study, we link changes in whole body glucose homeostasis to the altered GIPR-Q350 trafficking identified in cell-based studies (i.e., an enhanced TGN localization of activated GIPR-Q350) revealing a critical role for intracellular localization/traffic for GIPR function. It is well established that GPRC signal transduction is not limited to receptor activation at the plasma membrane but that internalized receptors continue to signal and that the post-activation traffic of GPCRs is a critical parameter in sculpting signal transduction (Calebiro et al., 2009; Ferrandon et al., 2009). Of note, GPCR transit through the TGN is critical for transcriptional regulation by GPCRs (Cheng and Filardo, 2012; Csaba et al., 2007; Escola et al., 2010; Godbole et al., 2017). Based on those data, we propose that the prolonged TGN dwell time of the GIPR-Q354 variant results in enhanced transcriptional effects that account, at least in 
part, for the increased glucose responsiveness of GIPR-Q354 $\beta$-cells. A test of this hypothesis requires broad unbiased transcriptional profiling.

The improved glucose disposal in an oral glucose challenge of GIPR-Q350 mice is not accompanied by elevated levels of insulin, which was unexpected in light of the enhanced insulin secretion from GIPR-Q350 islets stimulated by glucose or by glucose and GIP ex vivo. To defend against hypoglycemia, insulin levels and its activity in target tissues are tightly regulated by positive and negative feedback systems. The positive effects of GIP on insulin secretion and insulin action (e.g., effects on adipocytes) have been described (Baggio and Drucker, 2007; Khan et al., 2020; Mohammad et al., 2011). Based on the reduced GIP levels in an oral glucose challenge of GIPR-Q350 mice, we propose that there is a negative feedback regulation that matches GIP levels secreted from K-cells to the GIP-sensitivity of $\beta$-cells. The GIPR is expressed in a number of tissues, including white fat, brown fat, muscle and the brain, all tissues that contribute to regulation of whole-body metabolism. In our model the GIPR-Q350 variant is expressed in all these tissues and therefore additional studies that dissect the impact of the GIPRQ350 variant in these different tissues are required to uncover the molecular components of this feedback regulation.

GIPR-Q350 male mice are protected against diet-induced obesity. These results are in line with GWAS studies identifying GIPR-E354 major allele as a risk factor for obesity (Berndt et al., 2013; Graff et al., 2017). GIPR knockout mice are resistant to dietinduced obesity identifying a role for GIPR in regulation of body weight (Boylan et al., 2015; Miyawaki et al., 2002). The focus of our studies were on $\beta$-cells, and $\beta$-cellspecific ablation of GIPR mice does not prevent against diet induced obesity (Campbell et al., 2016), suggesting that $\beta$-cell GIPR alone is not sufficient to understand the mechanism of weight gain in these mice. Notably, restoring GIPR expression in white adipose tissue of whole-body GIPR knockout mice is sufficient to restore normal weight gain on a HFD, whereas adipose-specific knockout of GIPR protects against dietinduced obesity, highlighting the role of adipose GIPR (Joo et al., 2017; Ugleholdt et al., 2011). 
In our model the GIPR-Q350 variant is expressed in all tissues that normally express GIPR; therefore, the metabolic phenotype of the GIPR-Q350 variant reflects the sum of the effects on all these tissues. Activation of GIPR receptor-expressing cells of the hypothalamus suppresses food intake, suggesting a potential mechanism for the resistance of GIPR-Q350 mice to weight gain on a HFD (Adriaenssens et al., 2019). However, we did not observe a difference in food intake or any of the parameters we measured that are typically associated with weight control, including energy expenditure, respiratory exchange, activity, caloric loss to feces and digestive efficiency. A possible explanation is that the effect of GIPR-Q350 on weight gain is a sum effect in a number of tissues and that these individual changes are not detected in our metabolic cage analyses.

Pharmacological agonism of incretin hormones has been proposed as a treatment of T2D. GLP-1 receptor agonists were shown to impact satiety, induce weight loss, enhance GSIS and hereafter regulate glucose homeostasis (Htike et al., 2017; Shyangdan et al., 2011). In GIPR based therapy, there is a dichotomy between agonism and antagonism of the receptor (Khan et al., 2020; Killion et al., 2020). Studies have targeted either GIP (Barbosa-Yañez et al., 2019; Boylan et al., 2015) or GIPR (Killion et al., 2018) with antagonist antibodies and have revealed a protective effect against dietinduced body weight gain. Others have used GIPR peptide agonists to show that by chronically infusing either GIP analog (Mroz et al., 2019) or by a dual treatment with a GLP-1 analog (Finan et al., 2013), a decreased weight and metabolic benefits can be achieved. These discrepancies argue that a modulation rather than a complete abolition or chronic activation of GIPR activity is key to a better metabolism. Here we report that the intracellular trafficking of GIPR influences mice metabolism and is accountable for glucose homeostasis modulation and adequate hormonal secretion. Based on our findings, and because GIPR-E354 variant is reported as obesity promoting, it would be of interest to pharmacologically target the receptor, to make it adapt the same conformation of GIPR-Q354 variant which would have a positive impact on metabolism in obese and type 2 diabetic humans subjects. 
Overall, our study highlights the beneficial role of the naturally occurring GIPR-Q354 variant on glucose homeostasis, the impact of sex on this phenotype and open new perspectives in the exploration of GIPR polymorphism in obesity onset. 


\section{Acknowledgments}

We thank Marissa Cortopassi, Hayley Nicholls and David Cohen for their assistance with Promethion metabolic cages experiments. We thank the Weill Cornell Medicine Biochemistry Microscopy \& Image Analysis Core and the Human Islet and Adenovirus Core of the Einstein-Sinai Diabetes Research Center (NIH P30 DK 020541). We thank members of the McGraw lab.

This work was supported by NIH grant 1R01 DK096925 (T.E.M.) and by American Diabetes Association Postdoctoral Fellowship grant 1-19-PMF-026 (B.P.).

\section{Author Contributions}

L.Y. designed and conducted experiments, analyzed the data, prepared figures and wrote the manuscript. B.P. conducted experiments, analyzed the data and edited the manuscript. N.A. designed and conducted experiments and analyzed the data. D.S. assisted with animal studies. R.L. conducted experiments and analyzed the data. N.GB. and C.R. performed GSIS experiments. J.W. performed in vitro experiments. J.C.L. and A.G-O. supervised some experiments. T.E.M. conceived and supervised the project, designed experiments, analyzed the data and wrote the manuscript.

\section{Declaration of Interests}

The authors declare that there is no conflict of interest. 


\section{Figure Legends}

Figure 1: Post activation recycling of GIPR-Q354 is impaired in $\beta$ cells. MIN6 cells were electroporated with HA-GIPR-E354-GFP or HA-GIPR-Q354-GFP (A) Quantification of GIPR plasma membrane (PM) level to total distribution in basal and GIP-stimulated (100nM) cells for $1 \mathrm{~h}$. Data from individual experiments are normalized to the HA-GIPR-E354-GFP-electroporated cells in basal condition. (B) Cells were stimulated or not with GIP (100 nM) for $1 \mathrm{~h}$. Immunofluorescence shows HA-GIPRE354-GFP or HA-GIPR-Q354-GFP (green), TGN46 (magenta) and nuclei counterstained with DAPI (blue). Scale bar, $10 \mu \mathrm{m}$, zoom scale bar, $5 \mu \mathrm{m}$. Arrows show colocalization. Brightness was increased for HA-GIPR-Q354-GFP Basal condition for visualization purposes. (C) Cells were stimulated or not with GIP (100nM) for $1 \mathrm{~h}$ prior to incubation with anti-HA antibodies for the indicated times. Graph shows GIPR exocytosis rate in basal or GIP-stimulated cells. (D) Cells were stimulated with GIP (100nM) for $1 \mathrm{~h}$ followed by an up to $2 \mathrm{~h}$ washout. Graph shows quantification of GIPR plasma membrane (PM) level to total distribution at different time points. Data are mean \pm SEM. ${ }^{*} p<0.05,{ }^{* * *} p<0.001$ versus GIPR-E354 condition, \#\#p $<0.01$ versus GIPRQ354 condition.

Figure 2: GIPR-Q350 does not impact the insulin sensitivity of female mice. (A) GIPR-WT and GIPR-Q350 female mice weights were monitored over time. (B) Blood glucose was measured on random fed nine weeks old females. (C) GIPR-WT and GIPR-Q350 female mice were fasted for $6 \mathrm{~h}$ prior to injection with Insulin $(0.75 \mathrm{U} / \mathrm{kg})$ and their blood glucose levels were monitored for $1 \mathrm{~h}$. ( $\mathrm{n}=18-20$ mice/genotype). (D) GIPR-WT and GIPR-Q350 females were fasted for $6 \mathrm{~h}$ prior to co-injection with Insulin $(0.5 \mathrm{U} / \mathrm{kg})$ and GIP $(20 \mu \mathrm{mol} / \mathrm{kg})$ and their blood glucose levels were monitored for $2 \mathrm{~h}$. ( $\mathrm{n}=8 \mathrm{mice} /$ genotype).

Figure 3: GIPR-Q350 females have an enhanced glucose tolerance. (A) Blood glucose excursion and area under the curve (AUC, insert) over time after an oral glucose tolerance test (OGTT, $2 \mathrm{~g} / \mathrm{kg}$ ) in $6 \mathrm{~h}$ fasted GIPR-WT and GIPR-Q350 females. ( $n=8$ mice/genotype). (B and C) Plasma levels of Insulin (B) and GIP (C) before and at the indicated times after glucose administration $(2 \mathrm{~g} / \mathrm{kg})$. ( $\mathrm{n}=8 \mathrm{mice} / \mathrm{genotype})$. (D and 
E) Blood glucose excursion (D) and area under the curve (AUC, E) over time after an intraperitoneal glucose tolerance test $(2 \mathrm{~g} / \mathrm{kg}$ ) supplemented or not with GIP (20 $\mu \mathrm{mol} / \mathrm{kg}$ ) in $16 \mathrm{~h}$ fasted GIPR-WT and GIPR-Q350 females. ( $\mathrm{n}=5$ independent experiments). (F) Plasma levels of Insulin before and at 15 minutes after IP-GTT plus or minus GIP ( $n=4$ independent experiments). (G) GSIS performed on 8 to 10 technical replicates per condition of pooled islets of similar sizes isolated from GIPR-WT $(n=3)$ and GIPR-Q350 $(n=3)$ mice. Islets were incubated for 45 min with the indicated glucose concentrations with or without GIP (100 nM). Graph shows average insulin secretion in pooled experiments $(n=3)$. $(H)$ Insulin concentration in 20 islets from 8 animals was independently measured. Graph shows insulin concentration per islet. (I) Immunofluorescence of pancreatic islets. Staining shows Glucagon (green) and Insulin (magenta). Scale bar, $50 \mu \mathrm{m}$. (J) Relative mRNA expression of Gipr, Glut2, Glucokinase, Insulin and G/p1r in isolated islets from GIPR-WT and GIPR-Q350 females. Data are mean \pm SEM. ${ }^{*} p<0.05,{ }^{* *} p<0.01,{ }^{* *} p<0.001$ versus GIPR-WT condition, \#\#p < 0.01, \#\#p < 0.001 versus GIPR-Q350 condition.

Figure 4: GIPR-Q350 does not impact the insulin sensitivity of male mice. (A) GIPR-WT and GIPR-Q350 male mice weights were monitored over time. (B) Blood glucose was measured on random fed nine weeks old males. (C) GIPR-WT and GIPRQ350 male mice were fasted for $6 \mathrm{~h}$ prior to injection with Insulin $(0.75 \mathrm{U} / \mathrm{kg})$ and their blood glucose levels were monitored for $1 \mathrm{~h}$. ( $\mathrm{n}=18-20$ mice/genotype). (D) GIPR-WT and GIPR-Q350 males were fasted for $6 \mathrm{~h}$ prior to co-injection with Insulin $(0.75 \mathrm{U} / \mathrm{kg})$ and GIP $(20 \mu \mathrm{mol} / \mathrm{kg})$ and their blood glucose levels were monitored for $2 \mathrm{~h}$. $(\mathrm{n}=8$ mice/genotype).

Figure 5: GIPR-Q350 males are GIP hypersensitive. (A) Blood glucose excursion and area under the curve (AUC, insert) over time after an oral glucose tolerance test (OGTT, $2 \mathrm{~g} / \mathrm{kg}$ ) in $6 \mathrm{~h}$ fasted GIPR-WT and GIPR-Q350 males. ( $\mathrm{n}=8$ mice/genotype). (B and C) Plasma levels of Insulin (B) and GIP (C) before and the indicated times after glucose administration ( $2 \mathrm{~g} / \mathrm{kg}$ ). ( $\mathrm{n}=8 \mathrm{mice} / \mathrm{genotype}$ ). (D and E) Blood glucose excursion (D) and area under the curve (AUC, E) over time after an intraperitoneal glucose tolerance test $(2 \mathrm{~g} / \mathrm{kg})$ supplemented or not with GIP $(20 \mu \mathrm{mol} / \mathrm{kg})$ in $16 \mathrm{~h}$ fasted 
GIPR-WT and GIPR-Q350 males. ( $\mathrm{n}=7$ independent experiments). (F) Plasma levels of Insulin before and at 15 minutes after IP-GTT plus or minus GIP ( $n=4$ independent experiments) (G) GSIS performed on 8 to 10 technical replicates per condition of pooled islets of similar sizes isolated from GIPR-WT $(n=3)$ and GIPR-Q350 ( $n=3)$ mice. Islets were incubated for 45 min with the indicated glucose concentrations with or without GIP (100 nM). Graph shows average insulin secretion in pooled experiments $(n=2)$. $(\mathbf{H})$ Insulin concentration in 20 islets from 6 animals was independently measured. Graph shows insulin concentration per islet. (I) Immunofluorescence of pancreatic islets. Staining shows Glucagon (green) and Insulin (magenta). Scale bar, $50 \mu \mathrm{m}$. (J) Relative mRNA expression of Gipr, Glut2, Glucokinase, Insulin and Glp1r in isolated islets from GIPR-WT and GIPR-Q350 males. Data are mean \pm SEM. ${ }^{*} p<0.05,{ }^{* *} p<0.01,{ }^{* * *} p$ $<0.001$ versus GIPR-WT condition; \#\#p <0.01, \#\#\# < 0.001 versus GIPR-Q350 condition.

Figure 6: Male GIPR-Q350 mice are resistant to high fat diet-induced obesity. (A and B) 8 weeks old GIPR-WT and GIPR-Q350 male mice were fed a 60\% fat diet and their weights $(\mathbf{A})$ and $2 \mathrm{~h}$ fasted blood glucose levels $(\mathbf{B})$ were monitored over time. (C) Body fat composition as determined by MRI after 8 weeks of HFD feeding. (D and E) Weights (D) and blood glucose levels (E) after 17 weeks of HFD feeding. (F) Blood glucose excursion and area under the curve (AUC, insert) over time after an oral glucose tolerance test (OGTT, $2 \mathrm{~g} / \mathrm{kg}$ ) in $16 \mathrm{~h}$ fasted mice. (G and H) Plasma levels of Insulin (G) and GIP (H) before and at the indicated times after glucose administration (2 $\mathrm{g} / \mathrm{kg}$ ). ( $n=6$ mice/genotype). Data are mean \pm SEM. ${ }^{*} p<0.05,{ }^{* *} p<0.01,{ }^{* * *} p<0.001$ versus GIPR-WT condition. 


\section{Methods}

\section{Experimental models}

\section{Animals.}

C57BL/6J mice were purchased from Jackson Laboratory. We generated C57BL/6J GIPR-Q350 variant mice using CRISPR-CAS9 editing of ES cells, the equivalent of the GIPR-Q354 variant in human. We designed sgRNAs targeting the exon 12 on the GIPR gene, to introduce a point mutation in the GIPR sequence, as well as restriction sites to accurately genotype the founders. Genotyping was subsequently confirmed by PCR and by sequencing of $1000 \mathrm{bp}$ surrounding the mutation. Once founders were identified, mice were further bred back to $\mathrm{C} 57 \mathrm{BL} / 6 \mathrm{~J}$ mice for 10 generations after which male and female mice homozygous for Q350 allele were used for studies. The mice were generated in the WCM MSKCC animal facility.

Mice were maintained on a $12 \mathrm{~h} / 12 \mathrm{~h}$ ligh/dark cycle at room temperature and had ad libitum access to food and water. Mice were fed a chow diet (5053, PicoLab® Rodent Diet), except for the male mice study on high fat diet where mice were fed a $60 \%$ high fat diet (D12492i, Research Diets).

The Institutional Animal Care and Use Committee and the Research Animal Resource Center at Weill Cornell Medical College approved all animal procedures.

\section{Cell lines}

MIN6 cells were grown in DMEM (12100046, ThermoFisher Scientific) supplemented with 15\% Fetal bovine serum (FBS, 26140-095 ThermoFisher Scientific), PenicillinStreptomycin (15070063, ThermoFisher Scientific), 2mM Glutamine (25030-081, ThermoFisher Scientific), $50 \mu \mathrm{M} \beta$-mercaptoethanol (63689, Sigma-Aldrich) and kept at $37^{\circ} \mathrm{C}$ and $5 \% \mathrm{CO} 2$.

\section{Method details}

cDNA constructs and electroporation 
MIN6 cells were electroporated with $45 \mu \mathrm{g}$ of either HA-GIPR-E354-GFP or HA-GIPRQ354-GFP plasmids and cultured on coverslips. Experiments were conducted $24 \mathrm{~h}$ after electroporation. Cells were serum starved prior to incubation with GIP (100 nM, H3824.0500, Bachem) for the indicated times.

\section{Quantification of Surface to total GIPR}

Electroporated MIN6 cells cultured on coverslips were serum starved and treated with or without GIP (100 nM). Cells were fixed and stained with anti-HA antibodies (901503, BioLegend) without permeabilization. After PBS washes, cells were incubated with antimouse Cy3-conjugated antibodies. Cells were imaged by epifluorescence using a 20x objective (Leica Biosystems) and the intensity ratio of Cy3/GFP was used as an indicator of surface GIPR/total GIPR. Intensity for each cell was quantified using MetaMorph software.

\section{Quantification of GIPR exocytosis}

Electroporated MIN6 cells cultured on coverslips were serum starved and treated with or without GIP (100 nM) for $1 \mathrm{~h}$. Live cells were then incubated with anti-HA antibodies for indicated times. Cells were immediately fixed, permeabilized and incubated with antimouse Cy3-conjugated antibodies.

\section{Glucose tolerance test}

Oral glucose tolerance tests (OGTT) were performed in $6 \mathrm{~h}$ or $16 \mathrm{~h}$ fasted mice as indicated in figure legends. The glucose dose used was $2 \mathrm{~g} / \mathrm{kg}$.

Intraperitoneal glucose tolerance tests (IP-GTT) were performed in $16 \mathrm{~h}$ fasted mice. Mice were either ip injected with glucose at a dose of $2 \mathrm{~g} / \mathrm{kg}$ or with glucose $2 \mathrm{~g} / \mathrm{kg}$ and GIP $20 \mu \mathrm{mol} / \mathrm{kg}$.

For both OGTT and IP-GTT, blood glucose level was measured at indicated time points and blood was collected at 0,7 and 15 min in capillary microvettes coated with $\mathrm{K} 3$ EDTA and centrifuged for $15 \mathrm{~min}$ at $4^{\circ} \mathrm{C}$ to collect plasma.

\section{Insulin tolerance test}


Insulin tolerance tests (ITT) were performed in $6 \mathrm{~h}$ fasted mice. Mice were intraperitoneally injected with $0.75 \mathrm{U} / \mathrm{kg}$ Insulin. When co-injection with GIP $20 \mu \mathrm{mol} / \mathrm{kg}$ was performed during the ITT, male mice were injected with $0.75 \mathrm{U} / \mathrm{kg}$ Insulin and females $0.5 \mathrm{U} / \mathrm{kg}$ Insulin.

\section{Islets isolation}

Pancreata were perfused with Collagenase P (1.7 mg/ml, 11249002001, Sigma-Aldrich) via the pancreatic duct. Pancreata were collected, digested at $37^{\circ} \mathrm{C}$ for $15 \mathrm{~min}$ and washed in HBSS supplemented with $10 \%$ FBS. Islets were isolated using Histopaque ( (10771, Sigma-Aldrich) gradient. Islets were handpicked and allowed to recover overnight in RPMI (11879-020, ThermoFisher Scientific) media supplemented with 10\% FBS and $5.5 \mathrm{mM}$ Glucose.

\section{Glucose stimulated insulin secretion}

For each experiment, islets from 3-4 mice per genotype were pooled and incubated in basal KREBS media (119 mM NaCl, 100 mM HEPES, 23 mM KCl, 5 mM MgSO 40.75 $\mathrm{mM} \mathrm{Na}_{2} \mathrm{HPO}_{4}, 2 \mathrm{mM} \mathrm{KH} \mathrm{PO}_{4}, 25 \mathrm{mM} \mathrm{NaHCO}_{3}, 2 \mathrm{mM} \mathrm{CaCl}, 0.05 \%$ BSA) supplemented with $3 \mathrm{mM}$ Glucose for $2 \mathrm{~h}$ at $37^{\circ} \mathrm{C}$ and $5 \% \mathrm{CO}_{2} .8-10$ replicates of 5 islets per genotype were incubated in $3 \mathrm{mM}$ Glucose or $16.8 \mathrm{mM}$ Glucose with or without GIP (100 nM) for $45 \mathrm{~min}$ at $37^{\circ} \mathrm{C}$ and $5 \% \mathrm{CO}_{2}$. Supernatants were collected and immediately put on ice. Islets were lysed in RIPA buffer $(20 \mathrm{mM}$ Tris- $\mathrm{HCl}$ pH 7.5, 150 $\mathrm{mM} \mathrm{NaCl}, 1 \mathrm{mM}$ EDTA, 1 mM EGTA, 1\% NP-40, 1\% Na deoxycholate with antiphosphatase and anti-protease inhibitors) and were used to measure total protein content. Supernatants and protein lysates were stored at $-20^{\circ} \mathrm{C}$ until Insulin ELISA was performed.

\section{Quantitative RT-PCR}

$24 \mathrm{~h}$ after islets isolation, islets were lysed and RNA was extracted using the RNeasy kit (74106, Qiagen), according to the manufacturer's protocol. cDNA was obtained using the RNA to cDNA EcoDry Premix (639545, Takara). Quantitative PCR was performed with iQ SYBR Green Supermix (170-8884, Bio-Rad). Oligonucleotides used are listed in key resources table. 


\section{Immunofluorescence}

MIN6 cells were cultured on coverslips and fixed with $3.7 \%$ formaldehyde (F1635, Sigma-Aldrich). Cells were treated with $0.1 \%$ Triton $\mathrm{X}-100$ for $10 \mathrm{~min}$. Nonspecific binding was blocked by incubating cells in blocking buffer (10\% calf serum in PBS) for $30 \mathrm{~min}$. Incubation with primary antibodies was performed at $37^{\circ} \mathrm{C}$ for $1 \mathrm{~h}$ and incubation with secondary antibodies was performed at $37^{\circ} \mathrm{C}$ for $30 \mathrm{~min}$.

$7 \mu \mathrm{m}$ paraffin embedded mice pancreas sections were antigen retrieved in Citrate $\mathrm{pH}$ 6.0 and blocked with 3\% BSA, 10\% FBS in PBS buffer for $30 \mathrm{~min}$. Sections were incubated with primary antibodies in blocking buffer overnight at $4^{\circ} \mathrm{C}$ prior to incubation with Alexa 488 and Cy3-conjugated secondary antibodies for $30 \mathrm{~min}$ at room temperature.

Images were acquired using a Zeiss LSM 880 with Airyscan confocal microscope and prepared using ImageJ software.

\section{ELISA}

Insulin (81527, Crystal Chem) and GIP (EZRMGIP-55K, Sigma-Aldrich) ELISA kits were used to measure their level in the plasma. Protocols as provided by manufacturers were followed.

\section{Quantification and statistical analysis}

All experiments were repeated at least three times, except for the experiment in Figure $5 \mathrm{G}$, which was repeated twice. At least 5 mice per condition and per genotype were used as biological replicates for in vivo experiments. Results are expressed as means \pm SEM. Data were analyzed using Prism 6.0 software (GraphPad). Groups were compared with an analysis of variance (ANOVA) or a Student's t test, and a P value < 0.05 was considered as significantly relevant. 


\section{Supplemental Information}

Figure S1: GIPR-Q350 mice don't have a GLP-1 compensatory response. (A - D) Blood glucose excursion (A, C) and area under the curve (AUC, B, D) over time after an intraperitoneal glucose tolerance test $(2 \mathrm{~g} / \mathrm{kg}$ ) supplemented or not with GLP-1 (20 $\mu \mathrm{mol} / \mathrm{kg}$ ) in $16 \mathrm{~h}$ fasted GIPR-WT and GIPR-Q350 females (A and B) and males (C and D). ( $\mathrm{n}=$ 8-10 mice/condition).

Figure S2: Metabolic characterization of the male mice. GIPR-WT and GIPR-Q350 male mice were single housed and fed with HFD for 8 weeks. (A - C) Energy expenditure (A), distance traveled (B) and Respiratory exchange rate (C) were monitored during light and dark phases for 24 h. (D - H) Mice were single housed and fed with HFD for 8 weeks and food (D) and water (E) consumption, fecal mass (F) were monitored, residual energy in feces $(\mathbf{G})$ and digestive efficiency $(\mathbf{H})$ were measured for $24 \mathrm{~h}$. Data was adjusted to total body mass (TBM) when indicated. Data are mean \pm SEM. * $p<0.05$ versus GIPR-WT condition. 


\section{References}

Abdullah, N., Beg, M., Soares, D., Dittman, J.S., and McGraw, T.E. (2016).

Downregulation of a GPCR by $\beta$-Arrestin2-Mediated Switch from an Endosomal to a TGN Recycling Pathway. Cell Rep 17, 2966-2978.

Adriaenssens, A.E., Biggs, E.K., Darwish, T., Tadross, J., Sukthankar, T., Girish, M., Polex-Wolf, J., Lam, B.Y., Zvetkova, I., Pan, W., et al. (2019). Glucose-Dependent Insulinotropic Polypeptide Receptor-Expressing Cells in the Hypothalamus Regulate Food Intake. Cell Metabolism 30, 987-996.e986.

Almgren, P., Lindqvist, A., Krus, U., Hakaste, L., Ottosson-Laakso, E., Asplund, O., Sonestedt, E., Prasad, R.B., Laurila, E., Orho-Melander, M., et al. (2017). Genetic determinants of circulating GIP and GLP-1 concentrations. JCI Insight 2, e93306.

Almind, K., Ambye, L., Urhammer, S.A., Hansen, T., Echwald, S.M., Holst, J.J., Gromada, J., Thorens, B., and Pedersen, O. (1998). Discovery of amino acid variants in the human glucose-dependent insulinotropic polypeptide (GIP) receptor: the impact on the pancreatic beta cell responses and functional expression studies in Chinese hamster fibroblast cells. Diabetologia 41, 1194-1198.

Baggio, L.L., and Drucker, D.J. (2007). Biology of incretins: GLP-1 and GIP. Gastroenterology 132, 2131-2157.

Barbosa-Yañez, R.L., Markova, M., Dambeck, U., Honsek, C., Machann, J., Schüler, R., Kabisch, S., and Pfeiffer, A.F.H. (2019). Predictive effect of GIPR SNP rs10423928 on glucose metabolism liver fat and adiposity in prediabetic and diabetic subjects. Peptides, 170237-170237.

Berndt, S.I., Gustafsson, S., Mägi, R., Ganna, A., Wheeler, E., Feitosa, M.F., Justice, A.E., Monda, K.L., Croteau-Chonka, D.C., Day, F.R., et al. (2013). Genome-wide metaanalysis identifies 11 new loci for anthropometric traits and provides insights into genetic architecture. Nature genetics 45, 501-512.

Boylan, M.O., Glazebrook, P.A., Tatalovic, M., and Wolfe, M.M. (2015). Gastric inhibitory polypeptide immunoneutralization attenuates development of obesity in mice. Am J Physiol Endocrinol Metab 309, E1008-E1018.

Buchan, A.M.J., Polak, J.M., Capella, C., Solcia, E., and Pearse, A.G.E. (1978). Electronimmunocytochemical evidence for the $\mathrm{K}$ cell localization of gastric inhibitory polypeptide (GIP) im man. Histochemistry 56, 37-44.

Calebiro, D., Nikolaev, V.O., Gagliani, M.C., de Filippis, T., Dees, C., Tacchetti, C., Persani, L., and Lohse, M.J. (2009). Persistent cAMP-Signals Triggered by Internalized G-Protein-Coupled Receptors. PLOS Biology 7, e1000172. 
Campbell, J.E., Ussher, J.R., Mulvihill, E.E., Kolic, J., Baggio, L.L., Cao, X., Liu, Y., Lamont, B.J., Morii, T., Streutker, C.J., et al. (2016). TCF1 links GIPR signaling to the control of beta cell function and survival. Nat Med 22, 84-90.

Cheng, S.-B., and Filardo, E.J. (2012). Trans-Golgi Network (TGN) as a Regulatory Node for $\beta 1$-Adrenergic Receptor ( $\beta 1 \mathrm{AR}$ ) Down-modulation and Recycling. Journal of Biological Chemistry 287, 14178-14191.

Chepurny, O.G., Kelley, G.G., Dzhura, I., Leech, C.A., Roe, M.W., Dzhura, E., Li, X., Schwede, F., Genieser, H.-G., and Holz, G.G. (2010). PKA-dependent potentiation of glucose-stimulated insulin secretion by Epac activator 8-pCPT-2'-O-Me-cAMP-AM in human islets of Langerhans. American journal of physiology Endocrinology and metabolism 298, E622-E633.

Csaba, Z., Lelouvier, B., Viollet, C., El Ghouzzi, V., Toyama, K., Videau, C., Bernard, V., and Dournaud, P. (2007). Activated Somatostatin Type 2 Receptors Traffic In Vivo in Central Neurons from Dendrites to the Trans Golgi Before Recycling. Traffic 8, 820-834.

Drucker, D.J. (2006). The biology of incretin hormones. Cell Metabolism 3, 153-165.

Dupre, J., Ross, S.A., Watson, D., and Brown, J.C. (1973). Stimulation of insulin secretion by gastric inhibitory polypeptide in man. J Clin Endocrinol Metab 37, 826-828.

Ehses, J.A., Casilla, V.R., Doty, T., Pospisilik, J.A., Winter, K.D., Demuth, H.-U., Pederson, R.A., and Mclntosh, C.H.S. (2003). Glucose-Dependent Insulinotropic Polypeptide Promotes $\beta$-(INS-1) Cell Survival via Cyclic Adenosine MonophosphateMediated Caspase-3 Inhibition and Regulation of p38 Mitogen-Activated Protein Kinase. Endocrinology 144, 4433-4445.

Enya, M., Horikawa, Y., lizuka, K., and Takeda, J. (2014). Association of genetic variants of the incretin-related genes with quantitative traits and occurrence of type 2 diabetes in Japanese. Molecular genetics and metabolism reports 1, 350-361.

Escola, J.-M., Kuenzi, G., Gaertner, H., Foti, M., and Hartley, O. (2010). CC Chemokine Receptor 5 (CCR5) Desensitization: CYCLING RECEPTORS ACCUMULATE IN THE TRANS-GOLGI NETWORK. Journal of Biological Chemistry 285, 41772-41780.

Faivre, E., Gault, V.A., Thorens, B., and Hölscher, C. (2011). Glucose-dependent insulinotropic polypeptide receptor knockout mice are impaired in learning, synaptic plasticity, and neurogenesis. J Neurophysiol 105, 1574-1580.

Ferrandon, S., Feinstein, T.N., Castro, M., Wang, B., Bouley, R., Potts, J.T., Gardella, T.J., and Vilardaga, J.-P. (2009). Sustained cyclic AMP production by parathyroid hormone receptor endocytosis. Nature Chemical Biology 5, 734-742.

Finan, B., Ma, T., Ottaway, N., Müller, T.D., Habegger, K.M., Heppner, K.M., Kirchner, H., Holland, J., Hembree, J., Raver, C., et al. (2013). Unimolecular Dual Incretins 
Maximize Metabolic Benefits in Rodents, Monkeys, and Humans. Science Translational Medicine 5, 209 ra151.

Gabe, M.B.N., van der Velden, W.J.C., Gadgaard, S., Smit, F.X., Hartmann, B., Bräuner-Osborne, H., and Rosenkilde, M.M. (2019). Enhanced agonist residence time, internalization rate and signalling of the GIP receptor variant [E354Q] facilitate receptor desensitization and long-term impairment of the GIP system. Basic \& clinical pharmacology \& toxicology, 10.1111/bcpt.13289.

Godbole, A., Lyga, S., Lohse, M.J., and Calebiro, D. (2017). Internalized TSH receptors en route to the TGN induce local Gs-protein signaling and gene transcription. Nature Communications 8, 443.

Graff, M., Scott, R.A., Justice, A.E., Young, K.L., Feitosa, M.F., Barata, L., Winkler, T.W., Chu, A.Y., Mahajan, A., Hadley, D., et al. (2017). Genome-wide physical activity interactions in adiposity - A meta-analysis of 200,452 adults. PLoS genetics 13, e1006528-e1006528.

Harris, R.B.S., Bowen, H.M., and Mitchell, T.D. (2003). Leptin resistance in mice is determined by gender and duration of exposure to high-fat diet. Physiology \& Behavior $78,543-555$.

Holst, J.J., and Gromada, J. (2004). Role of incretin hormones in the regulation of insulin secretion in diabetic and nondiabetic humans. American journal of physiology Endocrinology and metabolism 287, E199-E206.

Htike, Z.Z., Zaccardi, F., Papamargaritis, D., Webb, D.R., Khunti, K., and Davies, M.J. (2017). Efficacy and safety of glucagon-like peptide-1 receptor agonists in type 2 diabetes: A systematic review and mixed-treatment comparison analysis. Diabetes Obes Metab 19, 524-536.

Hwang, L.-L., Wang, C.-H., Li, T.-L., Chang, S.-D., Lin, L.-C., Chen, C.-P., Chen, C.-T., Liang, K.-C., Ho, I.-K., Yang, W.-S., et al. (2010). Sex Differences in High-fat Dietinduced Obesity, Metabolic Alterations and Learning, and Synaptic Plasticity Deficits in Mice. Obesity 18, 463-469.

Ismail, S., Dubois-Vedrenne, I., Laval, M., Tikhonova, I.G., D'Angelo, R., Sanchez, C., Clerc, P., Gherardi, M.-J., Gigoux, V., Magnan, R., et al. (2015). Internalization and desensitization of the human glucose-dependent-insulinotropic receptor is affected by $\mathrm{N}$-terminal acetylation of the agonist. Molecular and Cellular Endocrinology 414, 202215.

Johnston, S.L., Souter, D.M., Tolkamp, B.J., Gordon, I.J., Illius, A.W., Kyriazakis, I., and Speakman, J.R. (2007). Intake Compensates for Resting Metabolic Rate Variation in Female C57BL/6J Mice Fed High-fat Diets. Obesity 15, 600-606.

Joo, E., Harada, N., Yamane, S., Fukushima, T., Taura, D., Iwasaki, K., Sankoda, A., Shibue, K., Harada, T., Suzuki, K., et al. (2017). Inhibition of Gastric Inhibitory 
Polypeptide Receptor Signaling in Adipose Tissue Reduces Insulin Resistance and Hepatic Steatosis in High-Fat Diet-Fed Mice. Diabetes 66, 868.

Khan, R., Tomas, A., and Rutter, G.A. (2020). Effects on pancreatic Beta and other Islet cells of the glucose-dependent insulinotropic polypeptide. Peptides 125, 170201.

Killion, E.A., Lu, S.-C., Fort, M., Yamada, Y., Véniant, M.M., and Lloyd, D.J. (2020). Glucose-Dependent Insulinotropic Polypeptide Receptor Therapies for the Treatment of Obesity, Do Agonists = Antagonists ? Endocrine reviews 41, bnz002.

Killion, E.A., Wang, J., Yie, J., Shi, S.D.H., Bates, D., Min, X., Komorowski, R., Hager, T., Deng, L., Atangan, L., et al. (2018). Anti-obesity effects of GIPR antagonists alone and in combination with GLP-1R agonists in preclinical models. Science Translational Medicine 10, eaat3392.

Kim, S.-J., Nian, C., Widenmaier, S., and Mclntosh, C.H.S. (2008). Glucose-Dependent Insulinotropic Polypeptide-Mediated Up-Regulation of $\beta$-Cell Antiapoptotic <em>Bcl$2</$ em> Gene Expression Is Coordinated by Cyclic AMP (cAMP) Response Element Binding Protein (CREB) and cAMP-Responsive CREB Coactivator 2. Molecular and Cellular Biology 28, 1644.

Kim, W., and Egan, J.M. (2008). The role of incretins in glucose homeostasis and diabetes treatment. Pharmacological reviews 60, 470-512.

Lamont, B.J., and Drucker, D.J. (2008). Differential antidiabetic efficacy of incretin agonists versus DPP-4 inhibition in high fat fed mice. Diabetes 57, 190-198.

Leech, C.A., Chepurny, O.G., and Holz, G.G. (2010). Chapter Ten - Epac2-Dependent Rap1 Activation and the Control of Islet Insulin Secretion by Glucagon-Like Peptide-1. In Vitamins \& Hormones, G. Litwack, ed. (Academic Press), pp. 279-302.

Mayo, K.E., Miller, L.J., Bataille, D., Dalle, S., Göke, B., Thorens, B., and Drucker, D.J. (2003). International Union of Pharmacology. XXXV. The Glucagon Receptor Family. Pharmacological Reviews 55, 167.

Miyawaki, K., Yamada, Y., Ban, N., Ihara, Y., Tsukiyama, K., Zhou, H., Fujimoto, S., Oku, A., Tsuda, K., Toyokuni, S., et al. (2002). Inhibition of gastric inhibitory polypeptide signaling prevents obesity. Nat Med 8, 738-742.

Mohammad, S., Patel, R.T., Bruno, J., Panhwar, M.S., Wen, J., and McGraw, T.E. (2014). A naturally occurring GIP receptor variant undergoes enhanced agonist-induced desensitization, which impairs GIP control of adipose insulin sensitivity. Mol Cell Biol 34, 3618-3629.

Mohammad, S., Ramos, L.S., Buck, J., Levin, L.R., Rubino, F., and McGraw, T.E. (2011). Gastric Inhibitory Peptide Controls Adipose Insulin Sensitivity via Activation of cAMP-response Element-binding Protein and p110 $\beta$ Isoform of Phosphatidylinositol 3Kinase. Journal of Biological Chemistry 286, 43062-43070. 
Mroz, P.A., Finan, B., Gelfanov, V., Yang, B., Tschöp, M.H., DiMarchi, R.D., and PerezTilve, D. (2019). Optimized GIP analogs promote body weight lowering in mice through GIPR agonism not antagonism. Molecular Metabolism 20, 51-62.

Nauck, M.A., and Meier, J.J. (2018). Incretin hormones: Their role in health and disease. Diabetes, obesity \& metabolism 20 Suppl 1, 5-21.

Nitz, I., Fisher, E., Weikert, C., Burwinkel, B., Li, Y., Möhlig, M., Boeing, H., Schreiber, S., Schrezenmeir, J., and Döring, F. (2007). Association analyses of GIP and GIPR polymorphisms with traits of the metabolic syndrome. Molecular nutrition \& food research 51, 1046-1052.

Pavlos, N.J., and Friedman, P.A. (2017). GPCR Signaling and Trafficking: The Long and Short of It. Trends in Endocrinology \& Metabolism 28, 213-226.

Pedroso, J.A.B., Camporez, J.P., Belpiede, L.T., Pinto, R.S., Cipolla-Neto, J., and Donato, J., Jr. (2019). Evaluation of Hepatic Steatosis in Rodents by Time-Domain Nuclear Magnetic Resonance. Diagnostics (Basel) 9.

Sauber, J., Grothe, J., Behm, M., Scherag, A., Grallert, H., Illig, T., Hinney, A., Hebebrand, J., Wiegand, S., Grüters, A., et al. (2010). Association of variants in gastric inhibitory polypeptide receptor gene with impaired glucose homeostasis in obese children and adolescents from Berlin. Eur J Endocrinol 163, 259-264.

Saxena, R., Hivert, M.-F., Langenberg, C., Tanaka, T., Pankow, J.S., Vollenweider, P., Lyssenko, V., Bouatia-Naji, N., Dupuis, J., Jackson, A.U., et al. (2010). Genetic variation in GIPR influences the glucose and insulin responses to an oral glucose challenge. Nature genetics $42,142-148$.

Seino, S., and Shibasaki, T. (2005). PKA-Dependent and PKA-Independent Pathways for cAMP-Regulated Exocytosis. Physiological Reviews 85, 1303-1342.

Sharma, R., Matsuzaka, T., Kaushik, M.K., Sugasawa, T., Ohno, H., Wang, Y., Motomura, K., Shimura, T., Okajima, Y., Mizunoe, Y., et al. (2019). Octacosanol and policosanol prevent high-fat diet-induced obesity and metabolic disorders by activating brown adipose tissue and improving liver metabolism. Scientific Reports 9, 5169.

Shibasaki, T., Takahashi, H., Miki, T., Sunaga, Y., Matsumura, K., Yamanaka, M., Zhang, C., Tamamoto, A., Satoh, T., Miyazaki, J.-i., et al. (2007). Essential role of Epac2/Rap1 signaling in regulation of insulin granule dynamics by cAMP. Proceedings of the National Academy of Sciences 104, 19333.

Shyangdan, D.S., Royle, P., Clar, C., Sharma, P., Waugh, N., and Snaith, A. (2011). Glucagon-like peptide analogues for type 2 diabetes mellitus. Cochrane Database Syst Rev 2011, CD006423-CD006423.

Song, W.-J., Seshadri, M., Ashraf, U., Mdluli, T., Mondal, P., Keil, M., Azevedo, M., Kirschner, Lawrence S., Stratakis, Constantine A., and Hussain, Mehboob A. (2011). 
Snapin Mediates Incretin Action and Augments Glucose-Dependent Insulin Secretion. Cell Metabolism 13, 308-319.

Torekov, S.S., Harsløf, T., Rejnmark, L., Eiken, P., Jensen, J.B., Herman, A.P., Hansen, T., Pedersen, O., Holst, J.J., and Langdahl, B.L. (2014). A Functional Amino Acid Substitution in the Glucose-Dependent Insulinotropic Polypeptide Receptor (GIPR) Gene Is Associated With Lower Bone Mineral Density and Increased Fracture Risk. The Journal of Clinical Endocrinology \& Metabolism 99, E729-E733.

Tortoriello, D.V., McMinn, J., and Chua, S.C. (2004). Dietary-Induced Obesity and Hypothalamic Infertility in Female DBA/2J Mice. Endocrinology 145, 1238-1247.

Trümper, A., Trümper, K., Trusheim, H., Arnold, R., Göke, B., and Hörsch, D. (2001). Glucose-Dependent Insulinotropic Polypeptide Is a Growth Factor for $\beta$ (INS-1) Cells by Pleiotropic Signaling. Molecular Endocrinology 15, 1559-1570.

Tseng, C.C., and Zhang, X.Y. (2000). Role of G protein-coupled receptor kinases in glucose-Dependent insulinotropic polypeptide receptor signaling. Endocrinology 141, 947-952.

Turcot, V., Lu, Y., Highland, H.M., Schurmann, C., Justice, A.E., Fine, R.S., Bradfield, J.P., Esko, T., Giri, A., Graff, M., et al. (2018). Protein-altering variants associated with body mass index implicate pathways that control energy intake and expenditure in obesity. Nature Genetics 50, 26-41.

Ugleholdt, R., Pedersen, J., Bassi, M.R., Füchtbauer, E.-M., Jørgensen, S.M., Kissow, H.-L., Nytofte, N., Poulsen, S.S., Rosenkilde, M.M., Seino, Y., et al. (2011). Transgenic rescue of adipocyte glucose-dependent insulinotropic polypeptide receptor expression restores high fat diet-induced body weight gain. J Biol Chem 286, 44632-44645.

Usdin, T.B., Mezey, E., Button, D.C., Brownstein, M.J., and Bonner, T.I. (1993). Gastric inhibitory polypeptide receptor, a member of the secretin-vasoactive intestinal peptide receptor family, is widely distributed in peripheral organs and the brain. Endocrinology 133, 2861-2870.

Vogel, C.I.G., Scherag, A., Brönner, G., Nguyen, T.T., Wang, H.-J., Grallert, H., Bornhorst, A., Rosskopf, D., Völzke, H., Reinehr, T., et al. (2009). Gastric inhibitory polypeptide receptor: association analyses for obesity of several polymorphisms in large study groups. BMC Med Genet 10, 19-19.

Wen, W., Cho, Y.-S., Zheng, W., Dorajoo, R., Kato, N., Qi, L., Chen, C.-H., Delahanty, R.J., Okada, Y., Tabara, Y., et al. (2012). Meta-analysis identifies common variants associated with body mass index in east Asians. Nature Genetics 44, 307-311.

Wheeler, M.B., Gelling, R.W., Hinke, S.A., Tu, B., Pederson, R.A., Lynn, F., Ehses, J., and Mclntosh, C.H.S. (1999). Characterization of the carboxyl-terminal domain of the rat glucose- dependent insulinotropic polypeptide (GIP) receptor. A role for serines 426 and 
427 in regulating the rate of internalization. Journal of Biological Chemistry $274,24593-$ 24601.

Xie, D., Zhong, Q., Ding, K.-H., Cheng, H., Williams, S., Correa, D., Bollag, W.B., Bollag, R.J., Insogna, K., Troiano, N., et al. (2007). Glucose-dependent insulinotropic peptide-overexpressing transgenic mice have increased bone mass. Bone 40,13521360.

Yabe, D., and Seino, Y. (2011). Two incretin hormones GLP-1 and GIP: comparison of their actions in insulin secretion and $\beta$ cell preservation. Prog Biophys Mol Biol 107, 248-256. 


\section{Figure 1}

A

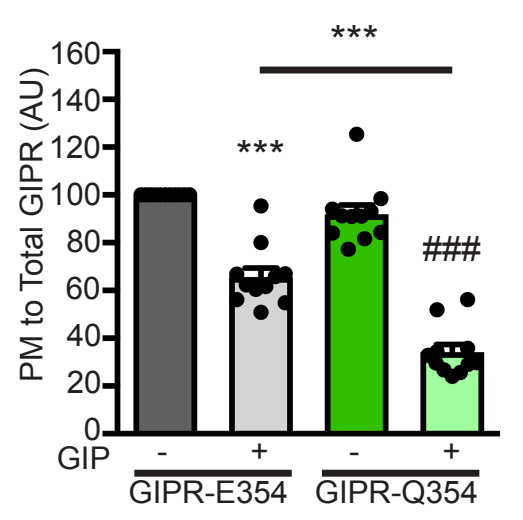

C

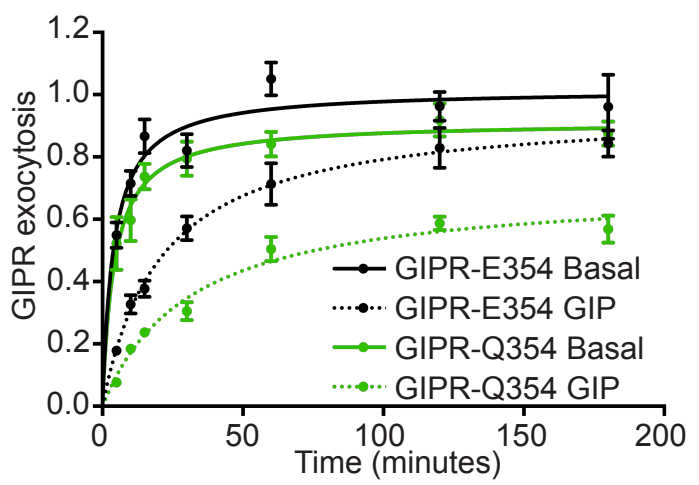

B
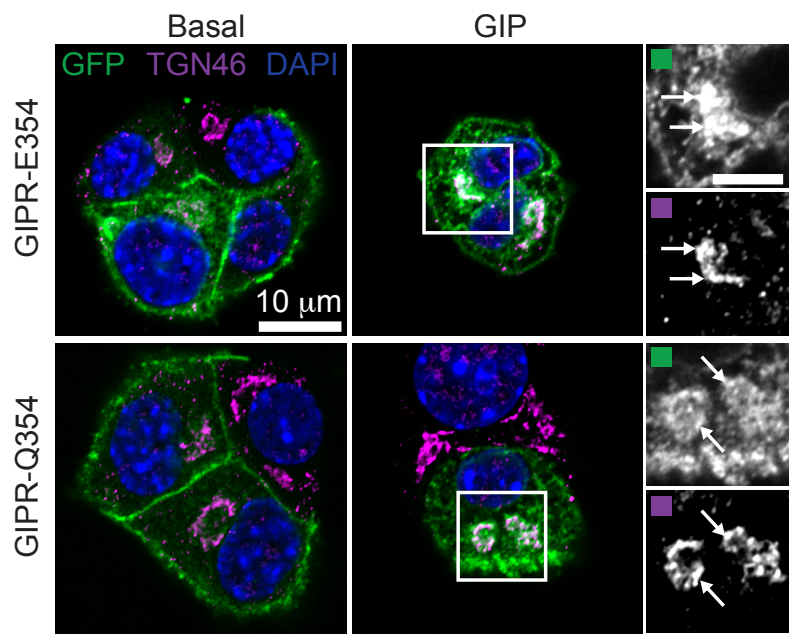

D $\underset{\text { stimulation }}{\text { GIP }}$ washout

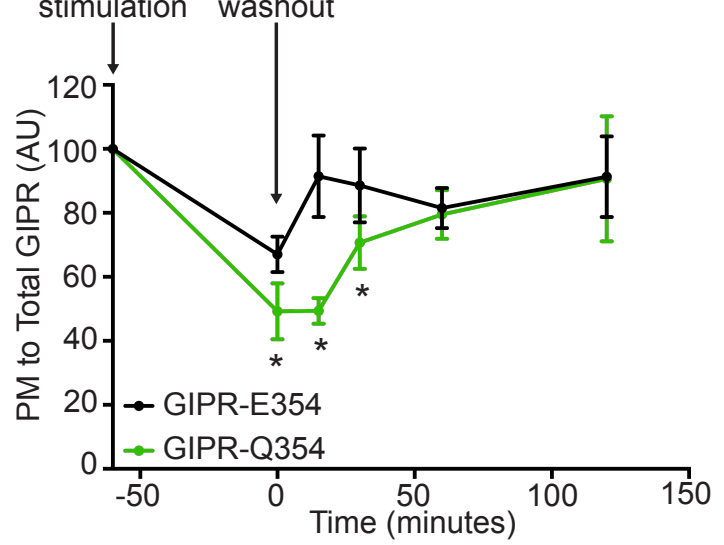

Figure 1: Post activation recycling of GIPR-Q354 is impaired in $\beta$ cells.

MIN6 cells were electroporated with HA-GIPR-E354-GFP or HA-GIPR-Q354-GFP (A) Quantification of GIPR plasma membrane (PM) level to total distribution in basal and GIP-stimulated (100nM) cells for $1 \mathrm{~h}$. Data from individual experiments are normalized to the HA-GIPR-E354-GFP-electroporated cells in basal condition. (B) Cells were stimulated or not with GIP (100 nM) for $1 \mathrm{~h}$. Immunofluorescence shows HA-GIPR-E354-GFP or HA-GIPR-Q354-GFP (green), TGN46 (magenta) and nuclei counterstained with DAPI (blue). Scale bar, $10 \mu \mathrm{m}$, zoom scale bar, $5 \mu \mathrm{m}$. Arrows show colocalization. Brightness was increased for HA-GIPR-Q354-GFP Basal condition for visualization purposes. (C) Cells were stimulated or not with GIP (100nM) for $1 \mathrm{~h}$ prior to incubation with anti-HA antibodies for the indicated times. Graph shows GIPR exocytosis rate in basal or GIP-stimulated cells. (D) Cells were stimulated with GIP (100nM) for $1 \mathrm{~h}$ followed by an up to $2 \mathrm{~h}$ washout. Graph shows quantification of GIPR plasma membrane (PM) level to total distribution at different time points. Data are mean \pm SEM. ${ }^{*} p<0.05,{ }^{* * *} p<0.001$ versus GIPR-E354 condition, \#\#\#p $<0.01$ versus GIPR-Q354 condition. 
Figure 2

A

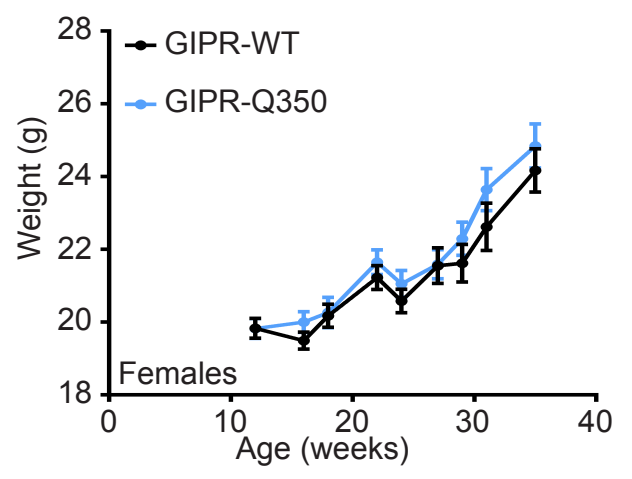

C

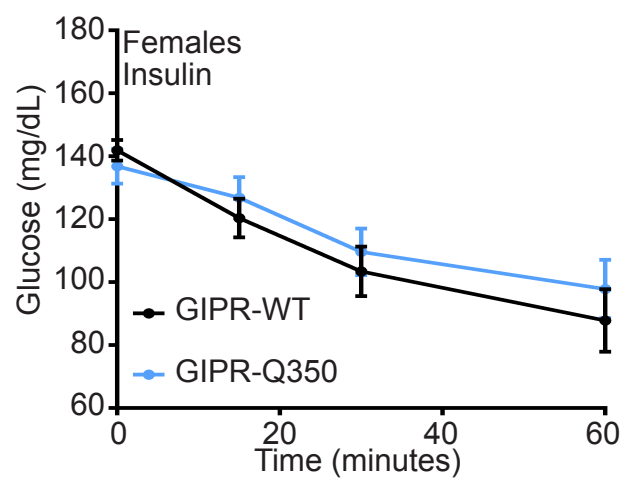

B

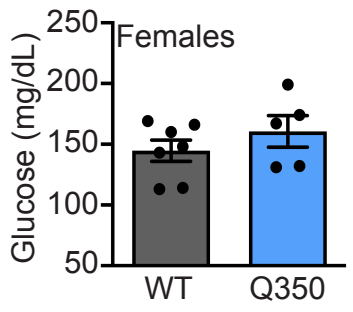

D

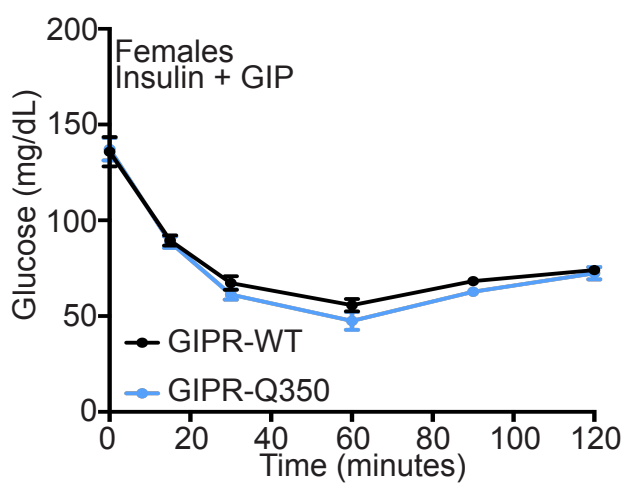

Figure 2: GIPR-Q350 does not impact the insulin sensitivity of female mice.

(A) GIPR-WT and GIPR-Q350 female mice weights were monitored over time. (B) Blood glucose was measured on random fed nine weeks old females. (C) GIPR-WT and GIPR-Q350 female mice were fasted for $6 \mathrm{~h}$ prior to injection with Insulin $(0.75 \mathrm{U} / \mathrm{kg})$ and their blood glucose levels were monitored for $1 \mathrm{~h}$. ( $\mathrm{n}=18-20 \mathrm{mice} / \mathrm{genotype})$. (D) GIPR-WT and GIPR-Q350 females were fasted for $6 \mathrm{~h}$ prior to co-injection with Insulin $(0.5 \mathrm{U} / \mathrm{kg})$ and GIP $(20 \mu \mathrm{mol} / \mathrm{kg})$ and their blood glucose levels were monitored for $2 \mathrm{~h}$. ( $\mathrm{n}=8$ mice/genotype). 
bioRxiv preprint doi: https://doi.org/10.1101/2020.05.12.091025; this version posted May 14, 2020. The copyright holder for this preprint (which Figure 3 was not certified by peer review) is the author/funder. All rights reserved. No reuse allowed without permission.
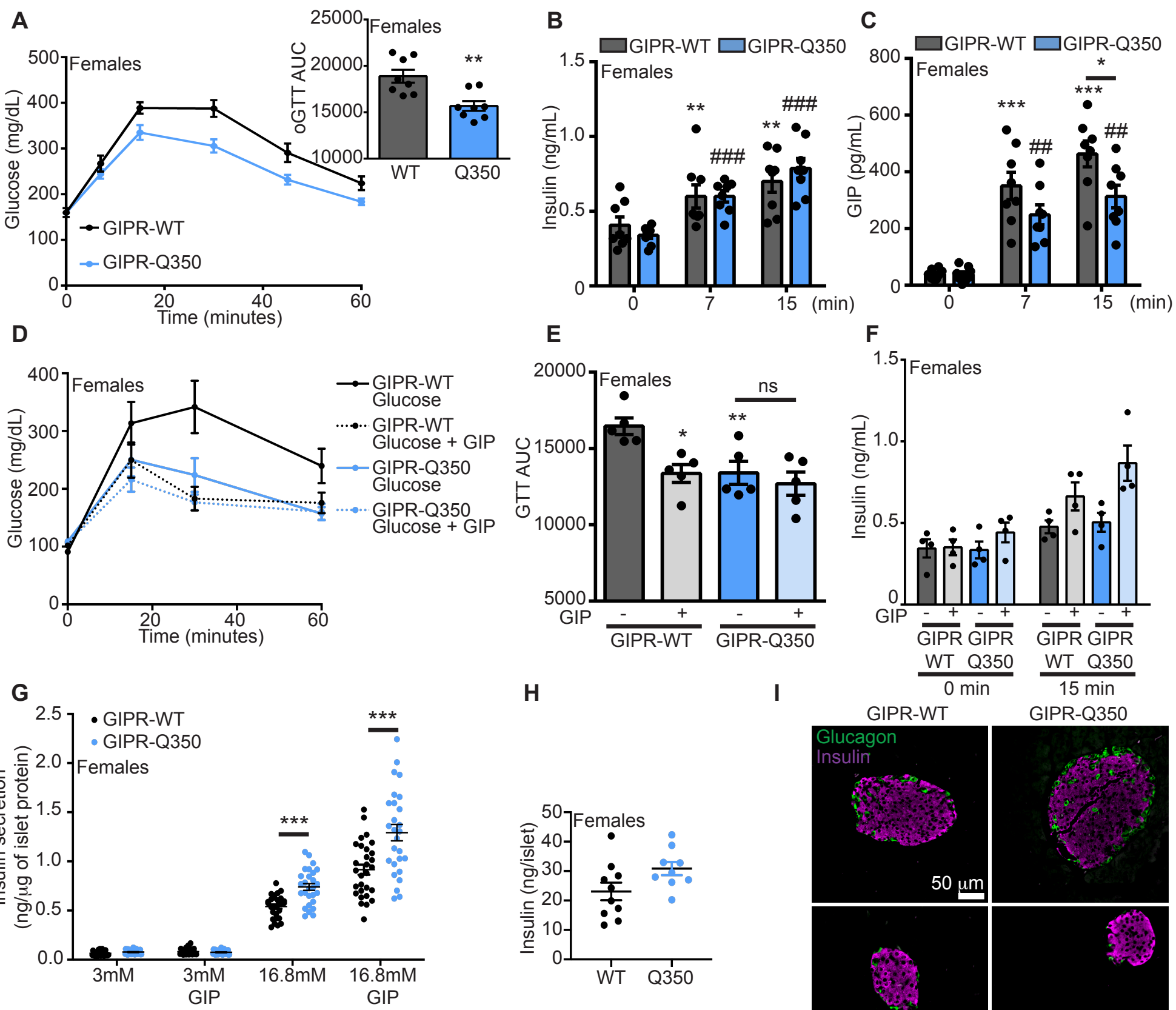

H

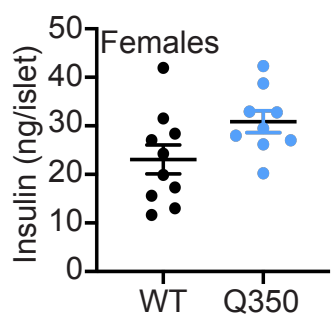

I
15 min

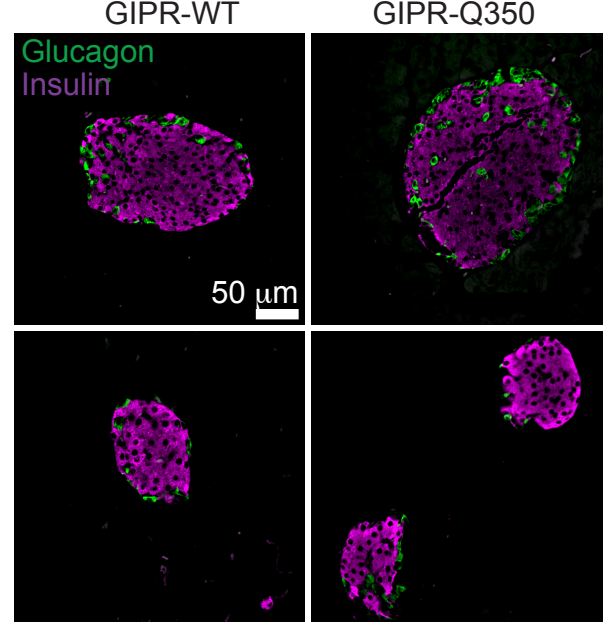

Figure 3: GIPR-Q350 females have an enhanced glucose tolerance.

(A) Blood glucose excursion and area under the curve (AUC, insert) over time after an oral glucose tolerance test (oGTT, $2 \mathrm{~g} / \mathrm{kg}$ ) in $6 \mathrm{~h}$ fasted GIPR-WT and GIPR-Q350 females. ( $n=8$ mice/genotype). (B and C) Plasma levels of Insulin (B) and GIP (C) before and at the indicated times after glucose administration $(2 \mathrm{~g} / \mathrm{kg})$. ( $\mathrm{n}=8 \mathrm{mice} / \mathrm{gen}$ otype). (D and E) Blood glucose excursion (D) and area under the curve (AUC, E) over time after an intraperitoneal glucose tolerance test $(2 \mathrm{~g} / \mathrm{kg})$ supplemented or not with GIP $(20 \mu \mathrm{mol} / \mathrm{kg})$ in $16 \mathrm{~h}$ fasted GIPR-WT and GIPR-Q350 females. ( $\mathrm{n}=5$ independent experiments). (F) Plasma levels of Insulin before and at 15 minutes after ip-GTT plus or minus GIP ( $n=4$ independent experiments). (G) GSIS performed on 8 to 10 technical replicates per condition of pooled islets of similar sizes isolated from GIPR-WT $(n=3)$ and GIPR-Q350 ( $n=3$ ) mice. Islets were incubated for 45 min with the indicated glucose concentrations with or without GIP (100 nM). Graph shows Graph shows insulin secretion in pooled experiments $(n=3)$. $(H)$ Insulin concentration in 20 islets from 8 animals was independently measured. Graph shows insulin concentration per islet. (I) Immunofluorescence of pancreatic islets. Staining shows Glucagon (green) and Insulin (magenta). Scale bar, $50 \mu \mathrm{m}$. (J) Relative mRNA expression of Gipr, Glut2, Glucokinase, Insulin and Glp1r in isolated islets from GIPR-WT and GIPR-Q350 females. Data are mean \pm SEM. ${ }^{*} p<0.05,{ }^{* *} p<0.01,{ }^{* * *} p<0.001$ versus GIPR-WT condition, \#\# < 0.01, \#\#\# < 0.001 versus GIPR-Q350 condition. 
Figure 4

A

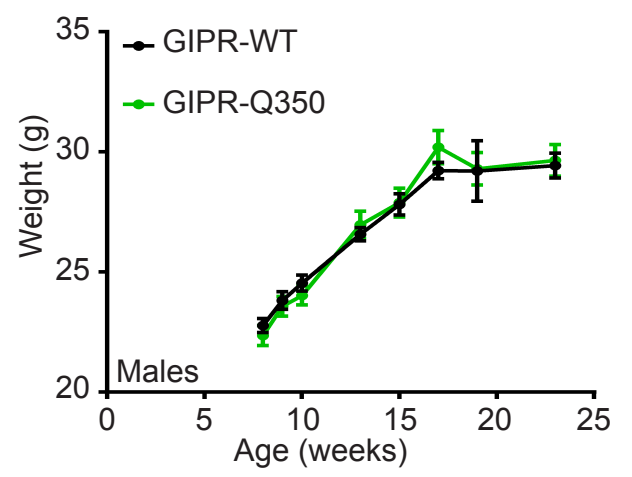

C

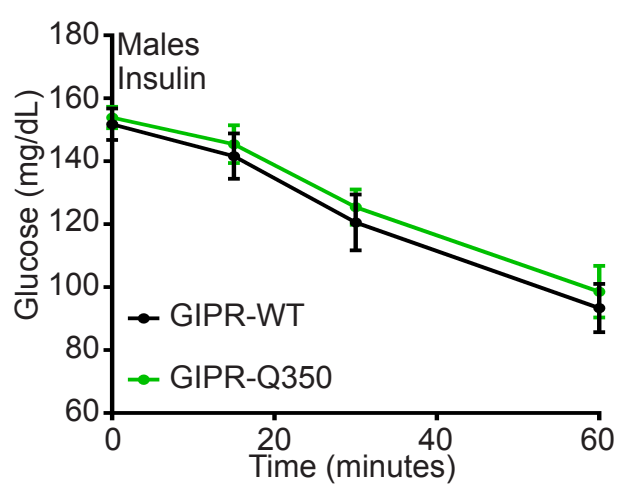

B

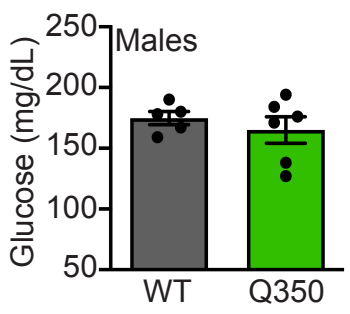

D

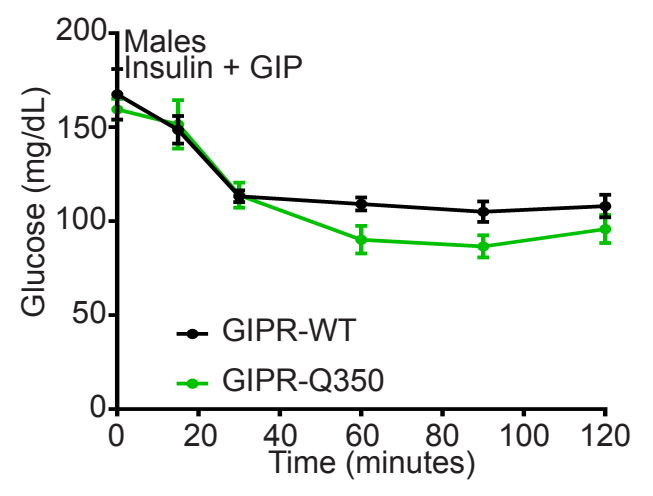

Figure 4: GIPR-Q350 does not impact the insulin sensitivity of male mice.

(A) GIPR-WT and GIPR-Q350 male mice weights were monitored over time. (B) Blood glucose was measured on random fed nine weeks old males. (C) GIPR-WT and GIPR-Q350 male mice were fasted for $6 \mathrm{~h}$ prior to injection with Insulin $(0.75 \mathrm{U} / \mathrm{kg})$ and their blood glucose levels were monitored for $1 \mathrm{~h}$. ( $\mathrm{n}=18-20$ mice/genotype). (D) GIPR-WT and GIPR-Q350 males were fasted for $6 \mathrm{~h}$ prior to co-injection with Insulin $(0.75 \mathrm{U} / \mathrm{kg})$ and GIP $(20 \mu \mathrm{mol} / \mathrm{kg})$ and their blood glucose levels were monitored for $2 \mathrm{~h}$. ( $\mathrm{n}=8$ mice/genotype). 
Figure 5
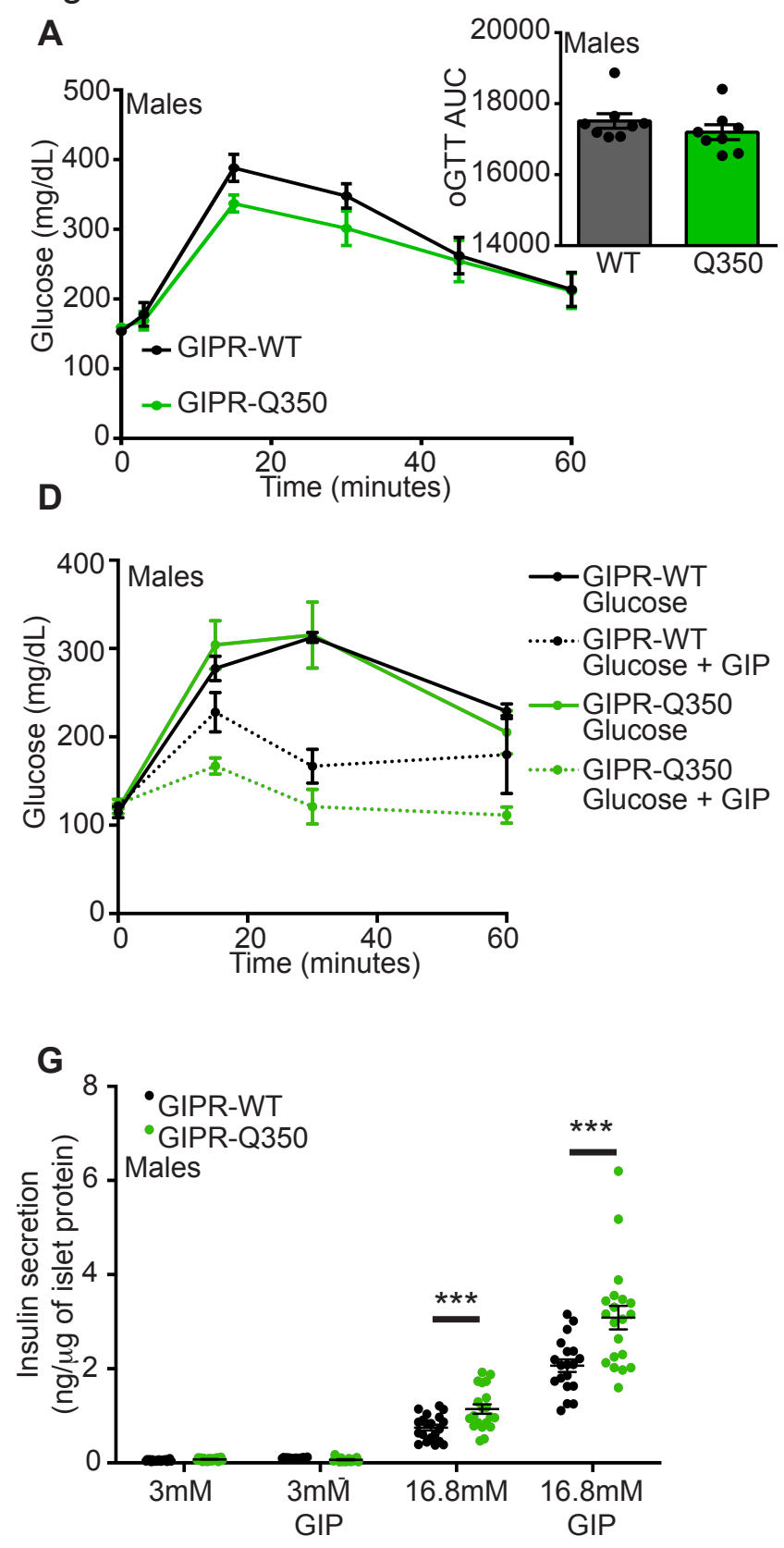

B

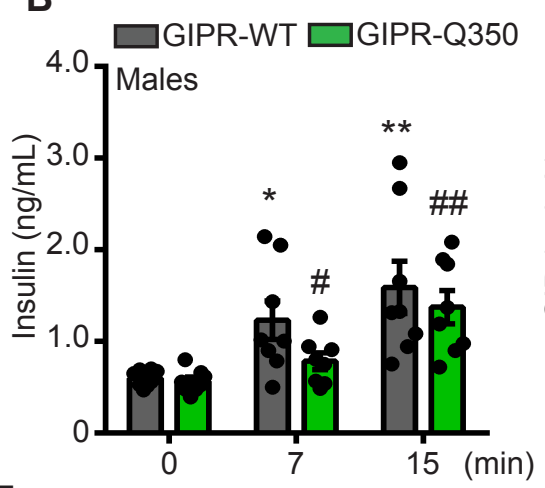

E

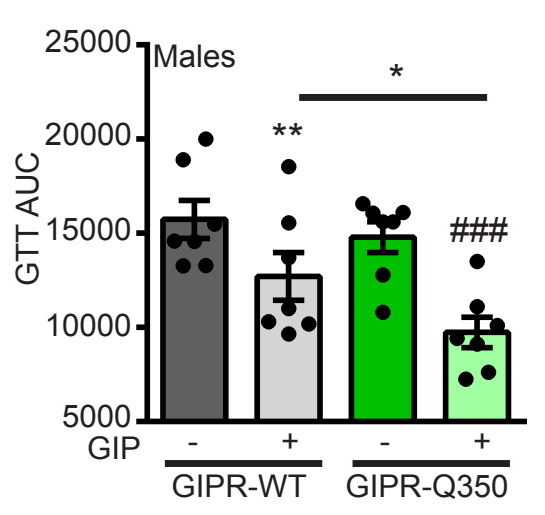

C

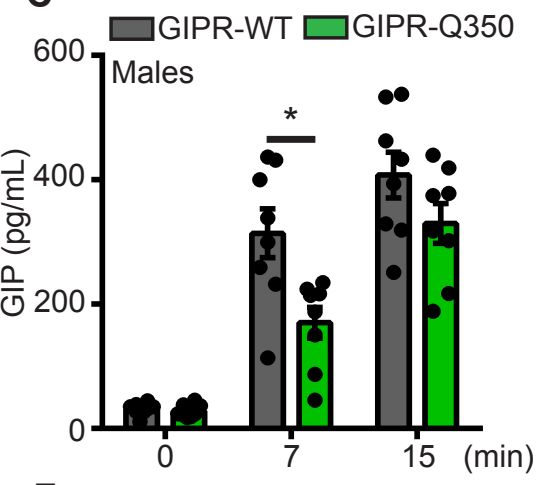

$F$

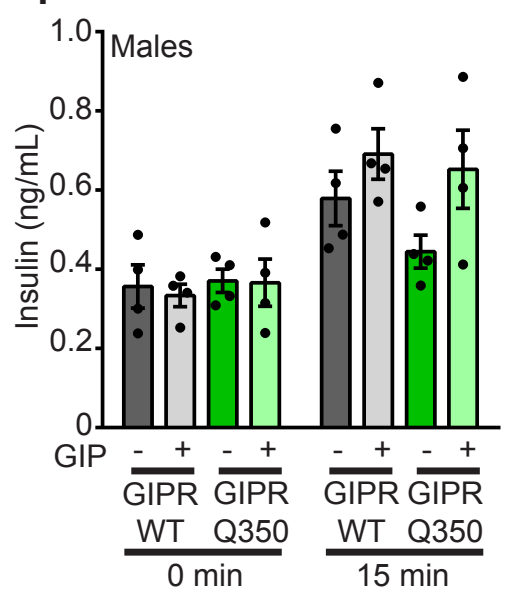

GIPR-WT
H I

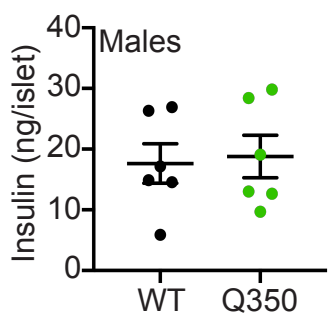

I

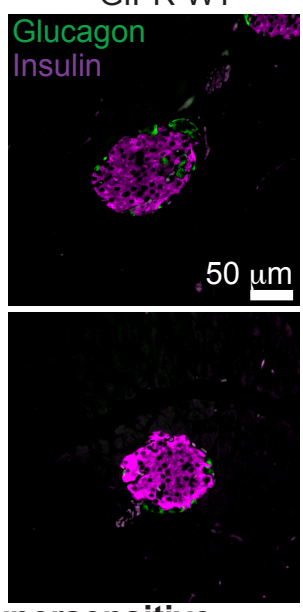

$50 \mu \mathrm{m}$

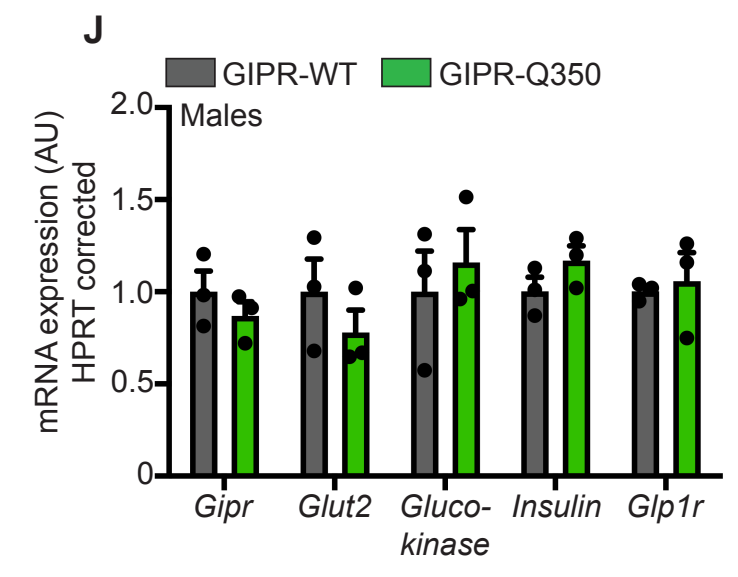

Figure 5: GIPR-Q350 males are GIP hypersensitive.

(A) Blood glucose excursion and area under the curve (AUC, insert) over time after an oral glucose tolerance test (oGTT, $2 \mathrm{~g} / \mathrm{kg}$ ) in $6 \mathrm{~h}$ fasted GIPR-WT and GIPR-Q350 males. ( $n=8$ mice/genotype). (B and C) Plasma levels of Insulin (B) and GIP (C) before and at the indicated times after glucose administration $(2 \mathrm{~g} / \mathrm{kg})$. ( $\mathrm{n}=8$ mice/genotype). (D and E) Blood glucose excursion (D) and area under the curve (AUC, E) over time after an intraperitoneal glucose tolerance test $(2 \mathrm{~g} / \mathrm{kg}$ ) supplemented or not with GIP $(20 \mu \mathrm{mol} / \mathrm{kg})$ in $16 \mathrm{~h}$ fasted GIPR-WT and GIPR-Q350 males. ( $n=7$ independent experiments). ( $F$ ) Plasma levels of Insulin before and at 15 minutes after ip-GTT plus or minus GIP ( $n=4$ independent experiments) (G) GSIS performed on 8 to 10 technical replicates per condition of pooled islets of similar sizes isolated from GIPR-WT $(n=3)$ and GIPR-Q350 $(n=3)$ mice. Islets were incubated for 45 min with the indicated glucose concentrations with or without GIP (100 nM). Graph shows insulin secretion in pooled experiments $(n=2)$. $(H)$ Insulin concentration in 20 islets from 6 animals was independently measured. Graph shows insulin concentration per islet. (I) Immunofluorescence of pancreatic islets. Staining shows Glucagon (green) and Insulin (magenta). Scale bar, $50 \mu \mathrm{m}$. (J) Relative mRNA expression of Gipr, Glut2, Glucokinase, Insulin and Glp1r in isolated islets from GIPR-WT and GIPR-Q350 males. Data are mean \pm SEM. ${ }^{*} p<0.05,{ }^{* *} p<0.01,{ }^{* *} p<0.001$ versus GIPR-WT condition; \#\#p <0.01, \#\#\# < 0.001 versus GIPR-Q350 condition. 
bioRxiv preprint doi: https://doi.org/10.1101/2020.05.12.091025; this version posted May 14, 2020. The copyright holder for this preprint (which

Figure 6 was not certified by peer review) is the author/funder. All rights reserved. No reuse allowed without permission.

A

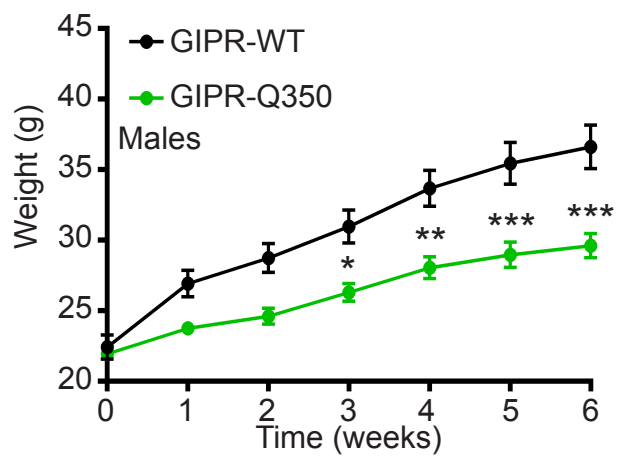

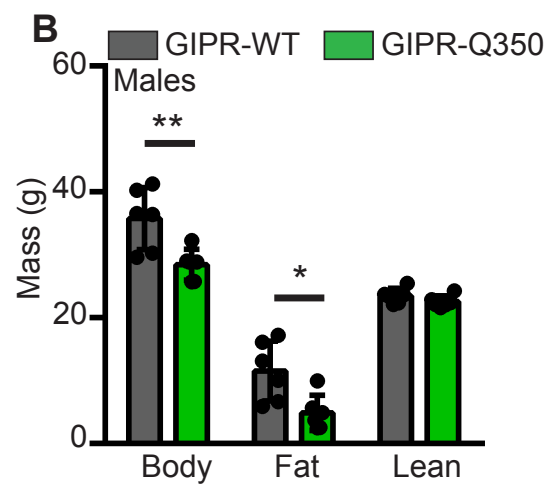

C

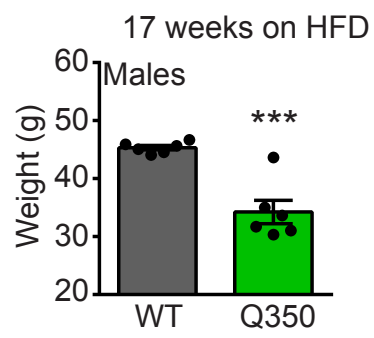

D

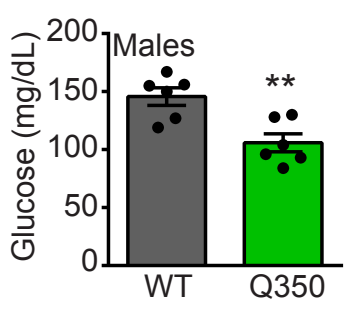

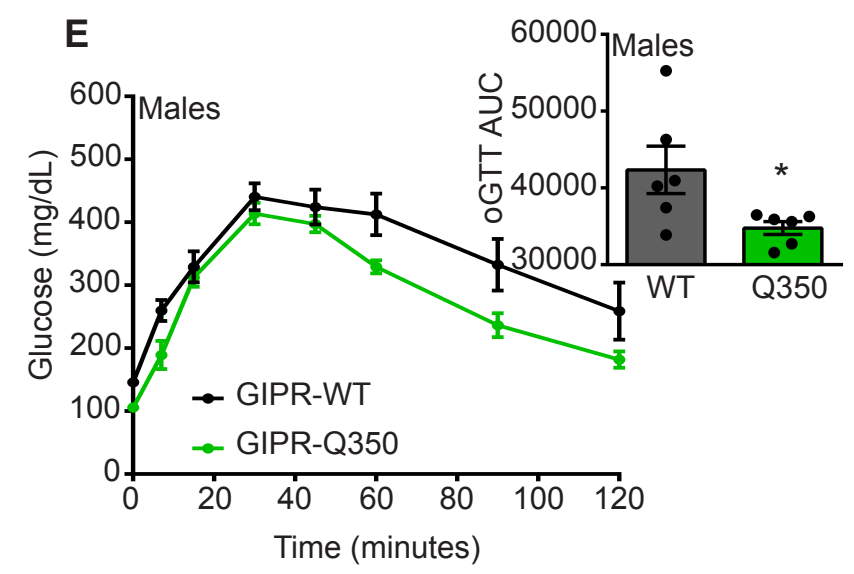
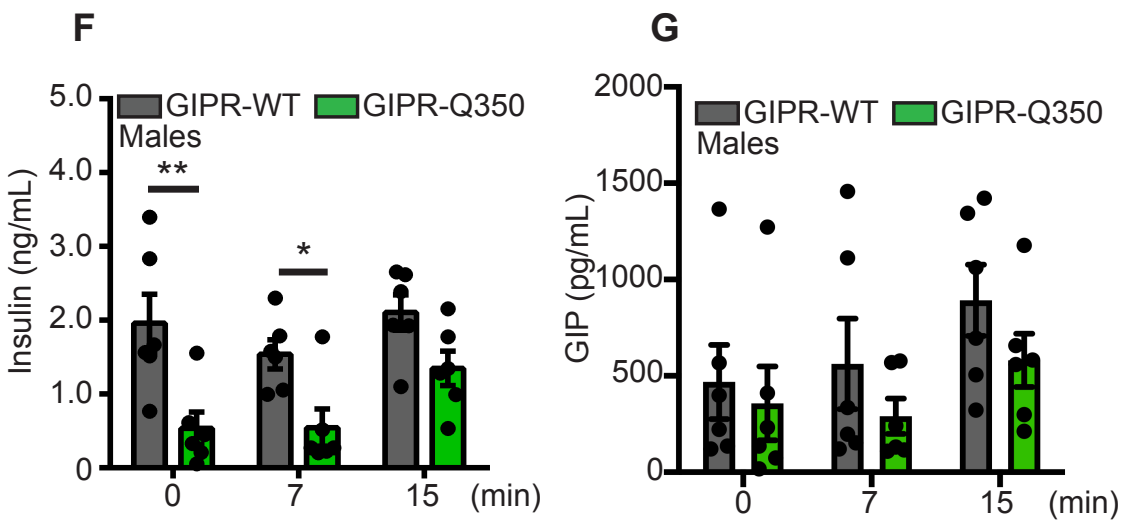

Figure 6: Male GIPR-Q350 mice are resistant to high fat diet-induced obesity.

(A) 8 weeks old GIPR-WT and GIPR-Q350 male mice were fed a $60 \%$ fat diet and their weights were monitored over time. (B) Body fat composition as determined by MRI after 8 weeks of HFD feeding. (C and D) Weights (C) and blood glucose levels (D) after 17 weeks of HFD feeding. (E) Blood glucose excursion and area under the curve (AUC, insert) over time after an oral glucose tolerance test (oGTT, $2 \mathrm{~g} / \mathrm{kg}$ ) in $16 \mathrm{~h}$ fasted mice. ( $\mathrm{F}$ and $\mathrm{G}$ ) Plasma levels of Insulin (F) and GIP (G) before and at the indicated times after glucose administration $(2 \mathrm{~g} / \mathrm{kg})$. ( $\mathrm{n}=6$ mice/genotype). Data are mean \pm SEM. ${ }^{*} p<0.05,{ }^{* *} p<0.01,{ }^{* * *} p<0.001$ versus GIPR-WT condition. 
A

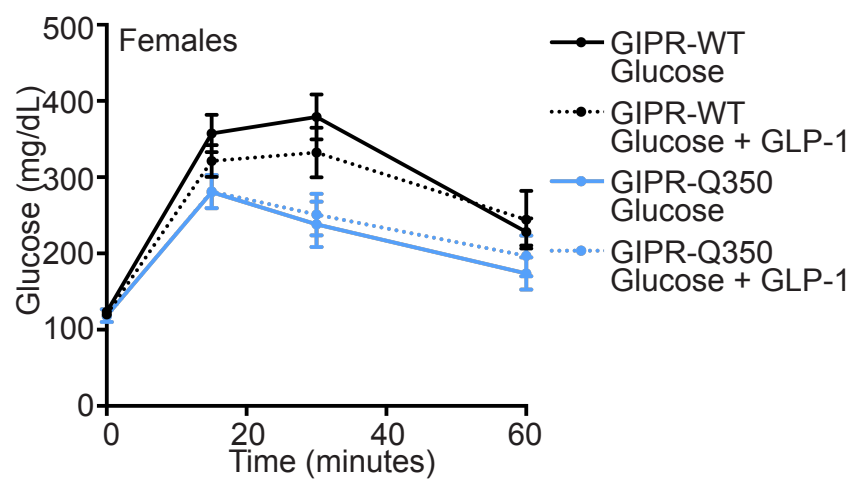

C

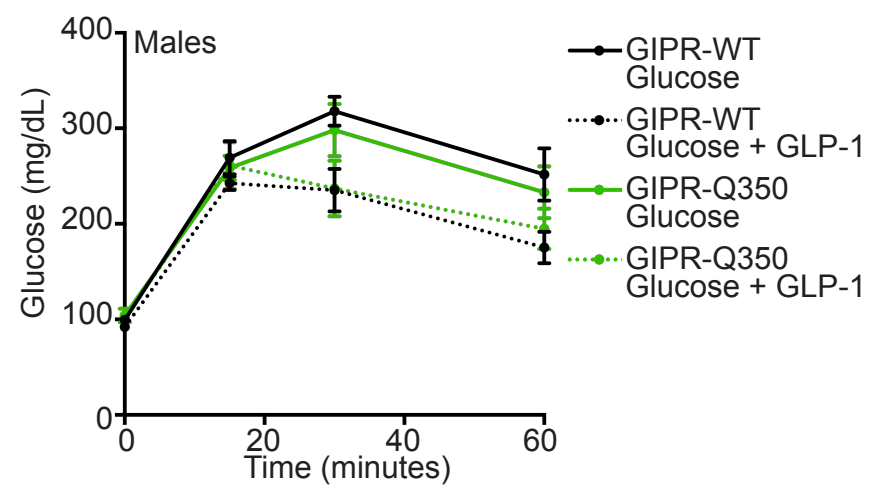

\section{B}

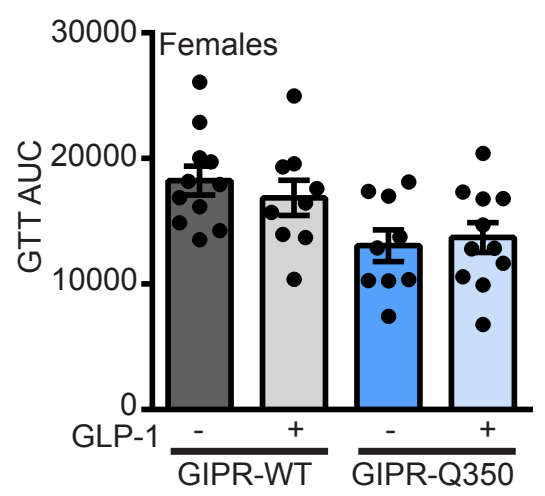

\section{D}

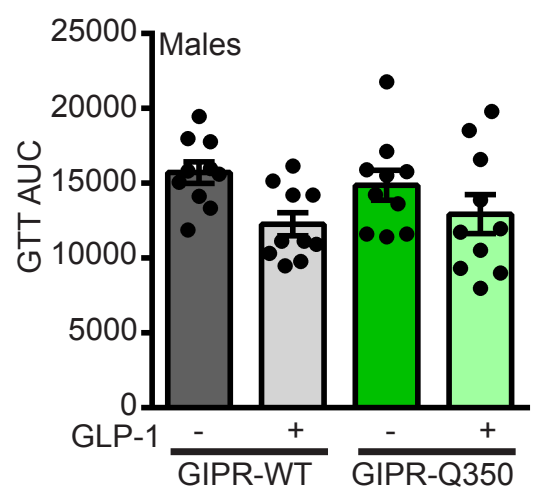

Figure S1: GIPR-Q350 mice don't have a GLP-1 compensatory response.

(A - D) Blood glucose excursion (A, C) and area under the curve (AUC, B, D) over time after an intraperitoneal glucose tolerance test $(2 \mathrm{~g} / \mathrm{kg})$ supplemented or not with GLP-1 $(20 \mu \mathrm{mol} / \mathrm{kg})$ in $16 \mathrm{~h}$ fasted GIPR-WT and GIPR-Q350 females (A and B) and males ( $C$ and D). $(n=8-10$ mice/condition). 


\section{Supplementary Figure 2}

$\square$ GIPR-WT $\square$ GIPR-Q350

A

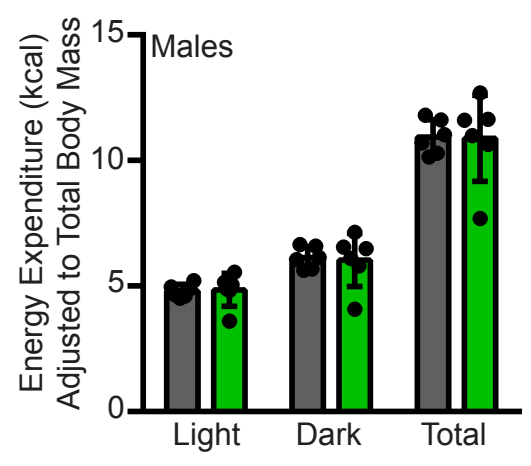

B

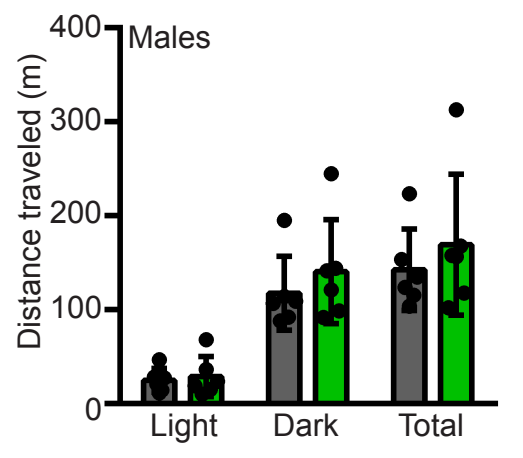

C

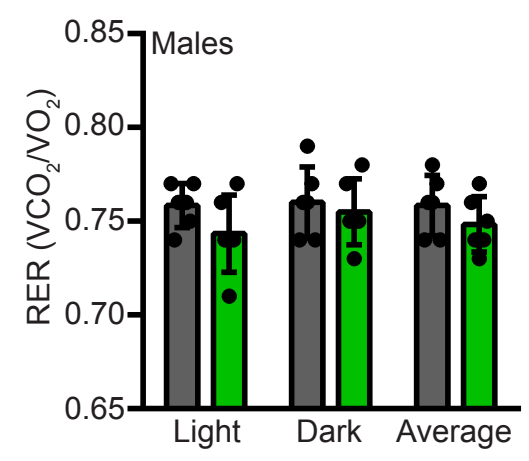

D

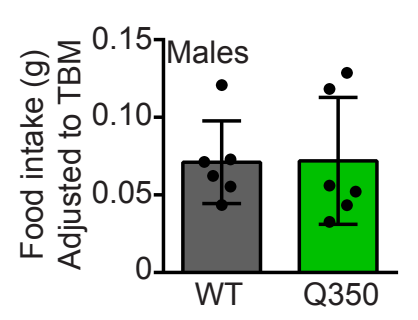

$E$

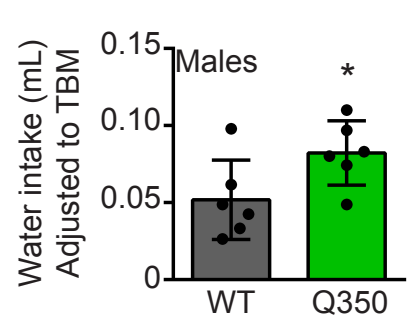

$\mathbf{F}$

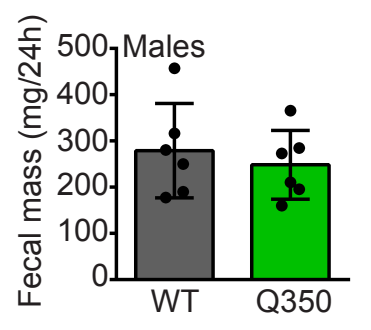

G

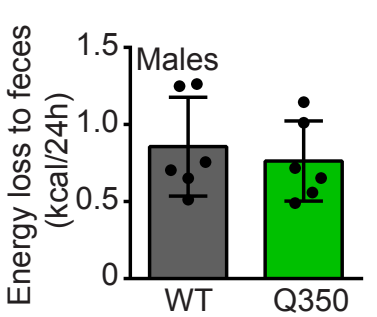

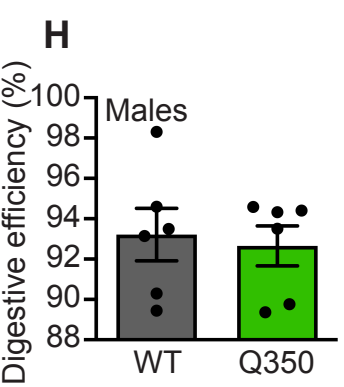

Figure S2: Metabolic characterization of the male mice.

GIPR-WT and GIPR-Q350 male mice were single housed and fed with HFD for 8 weeks. (A - C) Energy expenditure $(A)$, distance traveled $(B)$ and Respiratory exchange rate $(C)$ were monitored during light and dark phases for $24 \mathrm{~h}$. (D - H) Mice were single housed and fed with HFD for 8 weeks and food (D) and water (E) consumption, fecal mass (F) were monitored, residual energy in feces $(G)$ and digestive efficiency $(H)$ were measured for $24 \mathrm{~h}$. Data was adjusted to total body mass (TBM) when indicated. Data are mean \pm SEM. ${ }^{*} p<0.05$ versus GIPR-WT condition. 